\title{
LA REINA DEL (MELO)DRAMA. LA REPRESENTACIÓN CINEMATOGRÁFICA DE VICTORIA DEL REINO UNIDO
}

\author{
The (Melo)Drama Queen. Filmic \\ Representations of QueEn Victoria
}

\author{
Teresa Sorolla-Romero
}

Universitat Jaume I

\begin{abstract}
RESUMEN: En este texto nos proponemos destacar los aspectos más significativos de las estrategias de representación -estéticas y narrativas- que entretejen los discursos de los filmes dedicados a Victoria del Reino Unido durante las dos primeras décadas del siglo xxI: The Young Victoria (JeanMarc Valleé, 2009), Mrs. Brown (John Madden, 1997) y Victoria \& Abdul (Stephen Frears, 2017) identificando qué elecciones biográficas son destacan en ellas -qué aspectos se enfatizan, omiten o inventan- con el fin de comprender los mecanismos de articulación de las diferentes imágenes fílmicas de la monarca británica y emperatriz de la India.
\end{abstract}

Palabras clave: Victoria del Reino Unido; monarquía británica; drama de época; biopic.

ABSTRACT: In this article we intend to focus on the most significant aspects of the aesthetic and narrative strategies which interwave the filmic discourses devoted to Victoria of the United Kingdom along the first two decades of the $21^{\text {st }}$ century: The Young Victoria (Jean-Marc Valleé, 2009), Mrs. Brown (John Madden, 1997) and Victoria E Abdul (Stephen 
Frears, 2017). Our aim is to identify which biographical choices are emphasized -that is, which facets are highlighted, omitted or invented-in order to understand which mechanisms articulate several filmic images of the British monarch and Empress of the India.

Key Words: Queen Victoria; British Monarchy; Period Drama; Biopic.

\section{LA MUERTE}

Se deshacen los finos tules y el velo nupcial que envuelven, casi convirtiéndolo en crisálida, el cuerpo inerte, palidísimo, de la anciana reina Victoria (1819-1901). Como disolviendo la tela con el verde de las flores que la circundan, la representación del lecho de muerte de la soberana pintado por Sir Hubert von Herkomer remite a lo acuoso de una muerte casi ofeliana (fig. 1). La imagen cinematográfica de la reina muerta, que sucede al lienzo a una distancia de más de un siglo, encuentra un equilibrio entre el cuadro y la fotografía post mortem que sirvió de base a Herkomer, si bien compositivamente prevalece la huella del lienzo (fig. 2). Palmas verdes y lirios la rodean mientras, de entre su velo y vestido blanco, solamente emergen con discreción el rostro, las manos y -como se adivina también en el cuadrouna cruz entre estas. La composición centrada favorece el punto de vista del espectador en una imagen que se muestra menos fantasmal que el lienzo y también más ventajosa para observar el cuerpo de la reina que la fotografía que atesora la National Portrait Gallery (fig. 3), tomada probablemente por el mismo artista.

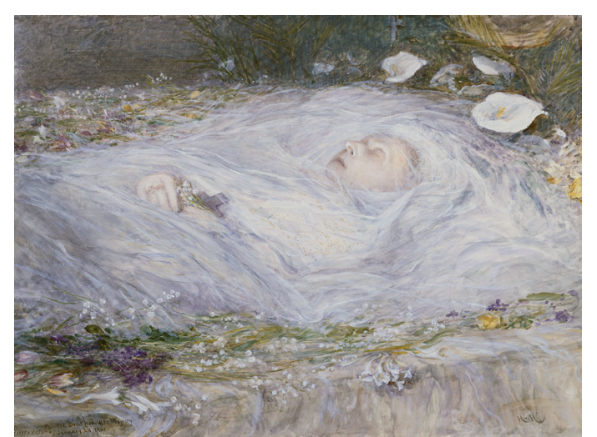

Fig. 1. Hubert von Herkomer, Queen Victoria on her death-bed, 1901, $430 \times 585 \mathrm{~mm}$, Osborne House.

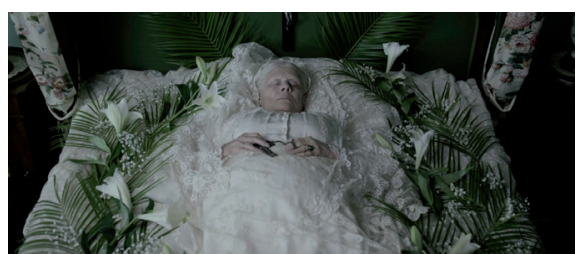

Fig. 2. La reina muerta en Victoria y Abdul, 2015. 
La fotografía post mortem de Victoria acusa el horror vacui del que suele tildarse al gusto decorativo de la época. Apenas se distingue el perfil de la soberana entre telas y flores, rodeado de efigies de su añorado príncipe Alberto (1919-1861) y otros objetos -armarios, cajas, cruces, plantas, cuadros- que pueblan el encuadre sin dar aire al cuerpo muerto.

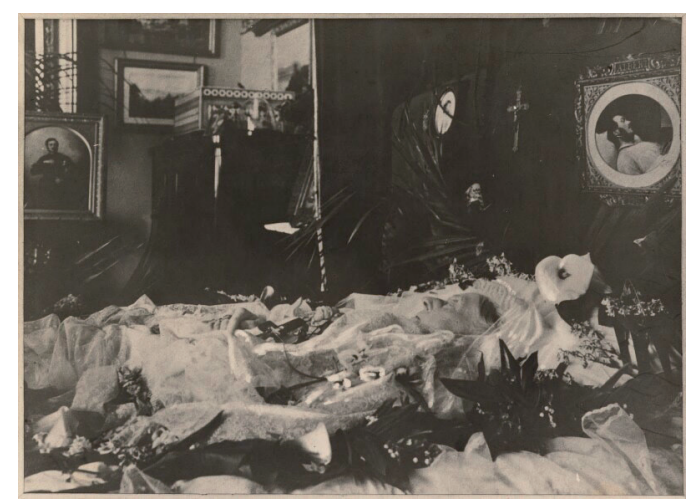

Fig. 3. Hubert von Herkomer, Queen Victoria on her deathbed, 1901, National Portrait Gallery.

La adoración de Victoria por los objetos convertidos en mementos de las sucesivas pérdidas que experimentó desde que subiera al trono en 1837 hasta su defunción en 1901, además de condicionar la configuración de los espacios privados que habitó -y los públicos en los que intervino- la acompañaría hasta su tumba. La reina, de carácter decididamente sentimental, pediría en secreto a su médico sir James Reid (1849-1923) que colocara en su ataúd, además de fotografías y recuerdos del príncipe Alberto y sus hijos, una fotografía y un pequeño estuche en su mano izquierda con un mechón de cabello de su fiel sirviente escocés John Brown (1826-1883), entre otros recuerdos suyos. ${ }^{1}$ No sería hasta la publicación de la biografía del doctor cuando todo ello saldría a la luz, puesto que el médico dispuso cuidadosamente los objetos de Brown, delicadamente tapados con el velo y los ornamentos florales, de forma que la familia real no los advirtiera al velar a la reina.

El apego de la mujer por la fotografía, entendida a medio camino entre la reliquia y la prueba fehaciente -atribución brindada por el positivismo decimonónico-, resulta tremendamente coherente aun siendo enfatizado por el aparatoso duelo que Victoria instaló tras la muerte de Alberto. La genética de la fotografía analógica requiere la presencia efectiva del objeto ante el dispositivo de registro, y con ello arrastra la ineludible huella del retratado y le embalsama

1. Raymond Lamont-Brown: John Brown: Queen Victoria's Highland Servant, Sutton, 2000. 
en el tiempo -particularmente cuando se trata de un retrato post mortem-. Su maldición consiste en convocar al retratado, al que ya no es, desde una inalienable, dolorosa ausencia. No en balde, Walter Benjamin concede al género del retrato la gracia de vehicular de forma privilegiada el «aura», aquella poética «aparición irrepetible de una lejanía, por cerca que pueda hallarse». ${ }^{2}$ Desde que la reina fuera fotografiada por primera vez en 1844 -probablemente por Henry Collen- hasta su muerte atesoró infinidad de álbumes, siguiendo el impulso con el que el príncipe Alberto promocionó sociedades, estudios y proyectos fotográficos. Ambos fueron invitados a patrocinar, por ejemplo, la Photographic Society of London en 1853, tras su apoyo a la fotografía durante la Gran Exposición de 1851. Con la mirada puesta en esta técnica como herramienta al servicio de la Historia, Alberto encargó al pionero Roger Fenton más de trescientos retratos de soldados británicos y campos de batalla de la guerra de Crimea que organizaría escrupulosamente en la cada vez más ingente Royal Collection. ${ }^{3}$ Victoria había gustado de posar junto con su esposo y sus hijos constantemente y, de hecho, la fotografía se convirtió poco menos que en un pasatiempo para buena parte de la familia real. ${ }^{4}$ Cuando la reina enviudó, aprehendiendo la fe de su difunto esposo en la capacidad preservativa de la fotografía, colgó sobre la mitad vacía del lecho real un retrato post mortem coloreado de Alberto y continuó haciéndose fotografiar, junto con sus hijos, alrededor del busto de mármol de él.

La imagen impenitentemente seria, dura, de la soberana se convirtió -en especial desde la eclosión y producción en masa de fotografías suyas en la década de 1860- en un importante referente iconográfico de su reinado, ${ }^{5}$ no exento de críticas por su afectación. ${ }^{6}$ Su inquebrantable imagen enlutada se vería quebrada, pero por los avances fotográficos que en la década de 1880 permitieron tiempos de exposición más cortos y por tanto retratos más rápidos e informales. La esquiva sonrisa de Victoria aparece así, mostrando una pequeña hilera de dientes que resulta impactante tras décadas de envarado recogimiento. Paradójicamente, era cuando la reina misma declaraba «God knows there is nothing to admire in my ugly old person $»^{7}$ que alguna chispa de vitalidad se escapaba en los retratos con sus nietos o los desfiles de sus Jubileos, de oro (1887) y de diamante (1897) (fig. 3a y fig. 3b).

2. Walter Benjamin: Sobre la fotografia, Pre-Textos, Valencia, 2004.

3. El príncipe Alberto, en contacto con el pionero de la fotografía Roger Fenton, incluso le animó incluso a instalar en Windsor un cuarto oscuro que sería utilizado durante años por la familia real. HELEN RAppaport: Queen Victoria. A Biographical Companion, ABC-CLIO, Santa Bárbara, 2003, p. 294.

4. Alan Hardy: Queen Victoria Was Amused, John Murray, London, 1976.

5. Sin perjuicio de los muchos retratos pictóricos realizados, entre otros artistas, por Franz Xavier Winterhalter, Heinrich von Angeli o Edwin Lanseer, el gusto artístico de la reina, menos consistente que el de su esposo, nunca se interesó por lo entonces novedoso de figuras como Turner, Millais, Burne-Jones, Watts o los impresionistas.

6. Frances Diamond y Ann Taylor: Crown and Camera: The Royal Family and Photography, Penguin, Harmondsworth, 1987.

7. Diamond y TAYlor, Crown and Camera, p. 69. 


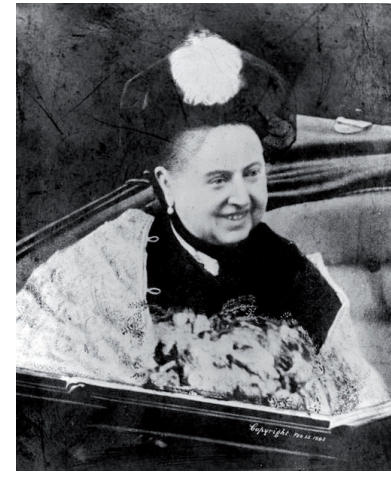

Fig. 3a. Charles Knight, Queen Victoria, 1887, $125 \times 102 \mathrm{~mm}$, National Portrait Gallery

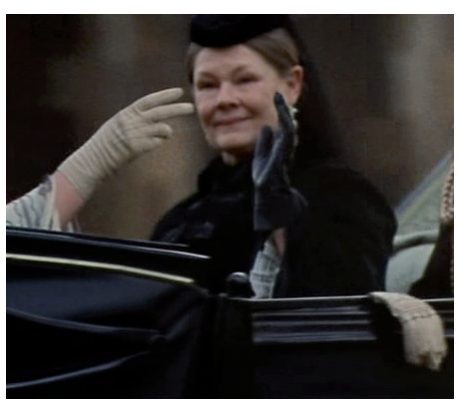

Fig. 3b. Victoria saludando en Mrs. Brown, 1997.

Un paralelismo puede ser trazado respecto a los filmes que nos ocupan en este escrito, pues son los que desarrollan la viudedad de la reina e incluso su senectud; aquellos que con más carisma, matices y coraje artístico la representan. Tanto el filme La reina Victoria (Young Victoria, Jean-Marc Valleé, 2009) como la serie televisiva Victoria (Daisy Goodwin, 2016-) se centran en la juventud y ascenso al trono de Victoria y sus primeros años de reinado y matrimonio. Los melodramas de época que conforman el grueso de los filmes de ficción dedicados a su biografía -o parte de ella- focalizan la narración en la relación afectiva, las más de las veces platónica, de la reina con diversos hombres, de entre los que se desmarca el príncipe Alberto. ${ }^{8}$ Desde el interés en la vertiente íntima de su vida, el cine contesta -reinventándola para el público- la intromisión que la figura de Victoria tuviera en el día a día de sus contemporáneos y que resultó clave para forjar la imagen de la monarquía bajo su reinado: a través de los periódicos, revistas satíricas, álbumes, espectáculos de linterna mágica, fotografías y otros dispositivos de la entonces naciente cultura visual de masas, la reina y su familia entraban en la cotidianidad de sus súbditos obteniendo una publicidad -tanto elogiosa como crítica- sin precedentes. ${ }^{9}$

Lo convencional del lenguaje cinematográfico que vehicula estos dos relatos se refleja en lo blando y buenista de la perspectiva que construye a la pareja real -ambos inteligentes, atractivos, leales, moralmente intachables y preocupados por los asuntos políticos de su tiempo-. Son, en cambio -como en las

8. No hemos podido abarcar en el texto de forma cuidadosa la representación de otros hombres presentes en las cintas -y en historiografía biográfica de la reina- como los primeros ministros lord Melbourne, sir Robert Peel, Benjamin Disraeli o el príncipe de Gales. Su tratamiento cinematográfico, digno de mención, esperamos poder tratarlo en futuros trabajos.

9. Una imagen mucho más omnipresente, cercana, familiar y menos idealizada en lo estético que la de sus predecesores en el trono, aunque no por ello menos autoconsciente, hasta el punto de que «It was not that Victoria's image was disseminated by photographs. The royal image itself became photographic». JOHN Plunkett: Queen Victoria: First Media Monarch, Oxford University Press, Oxford, 2003, p. 7. 
fotografías- las aproximaciones a una Victoria acorazada, irascible, desdeñosa y, con todo, deseosa de sentirse protegida y amada las que más aristas de la estética y narrativa fílmica exploran. Nos referimos a Su majestad Mrs. Brown (Mrs. Brown, John Madden, 1997) y La reina Victoria y Abdul (Victoria \& Ab$d u l$, Stephen Frears, 2017). En este texto nos proponemos destacar los aspectos más significativos de las estrategias de representación que entretejen los discursos de los filmes dedicados a Victoria del Reino Unido durante las dos primeras décadas del siglo XXI, ampliando y complementando trabajos como el análisis del guion y forma fílmica que de Mrs. Brown realizan Ford y Mitchell ${ }^{10}$ o los interrogantes planteados por Kinzler, ${ }^{11}$ desde la perspectiva de género, a propósito de The Young Victoria. ${ }^{12}$ Procuraremos identificar los aspectos más relevantes de su biografía que se destacan, omiten o inventan para comprender los mecanismos de articulación de las diferentes imágenes fílmicas de la emperatriz británica. Con tal fin, nos deslizaremos por la ficción filmada desde la juventud de la reina hasta sus últimos años, pese a que este no sea el orden de estreno los filmes, y nos detendremos en aspectos puntuales presentes en los tres desde distintas perspectivas.

\section{LA MADRE}

Dos retratos -hasta cierto punto contradictorios- de Victoria de SajoniaCoburgo-Saafeld (1786-1861), duquesa de Kent y madre de Victoria, la han sobrevivido como personaje histórico. Sin embargo, el de dulce anciana rodeada de nietos y leales sirvientes, sufriendo en silencio y piadosamente el dolor de una enfermedad terminal, no ha trascendido a su imagen cinematográfica. Es otra mujer muy distinta la que retratan tanto la serie Victoria ${ }^{13}$ como The Young Victoria: «a self-obsessed, histrionic, and impetuous virago, forever making unreasonable demands about her own status and income and in the process alienating most of the British royal family into which she had married». ${ }^{14}$ Esta última llega a retratar, a modo de prólogo, algunos de los episodios más

10. Elizabeth A. Ford, Deborah C. Mitchell: Royal Portraits in Hollywood. Filming the Lives of Queens, The University of Kentucky Press, Lexington, 2009.

11. Julia KinZler: «Visualising Victoria: Gender, Genre and History in The Young Victoria (2009)», en Neo-Victorian Studies, 4 (2), 2011, pp. 49-65.

12. Pese al interés merecedor de análisis de filmes anteriores en los que la reina aparece o protagoniza, como La reina Victoria (Victoria the Great, Herbert Wilcox, 1937), Sixty Glorious Years (Herbert Wilcox, 1938), La vida privada de Sherlock Holmes (The Private Life of Sherlock Holmes, Billy Wilder, 1970) e incluso Basil, el ratón superdetective (The Great Mouse Detective, Ron Clements, Burny Mattinson, 1986) o Mr. Turner (Mike Leigh, 2014), acotamos nuestro estudio a los tres más recientes y relacionados entre ellos.

13. Descartamos aquí el análisis de la serie, por falta de espacio. No obstante, llevaremos a cabo alguna mención puntual a esta, puesto que desarrolla la subida al trono, cortejo y primeros años de matrimonio de Victoria y, en este sentido, resulta interesante el paralelismo con The Young Victoria.

14. Helen Rappaport: Queen Victoria. A Biographical Companion, abC-Clio, Santa Bárbara, 2003, p. 226. 
significativos de la infancia y primera adolescencia de Victoria, sucedidos bajo el aislamiento y férreo control del Kengsinton System, ideado por la duquesa de Kent y su auditor y consejero sir John Conroy (1786-1854) -este último, presentado sin excepción como un ser codicioso, manipulador e incluso violento-.$^{15}$ La confianza de la duquesa en Conroy, que la defraudó financieramente de forma sistemática, en la organización de la vida de su hija enturbió las relaciones tanto con Guillermo IV como con ella misma de forma prácticamente irreparable - una vez reina, Victoria, que jamás perdonaría el comportamiento insultante y manipulador de Conroy para con ella, determinaría que su madre no solamente había sido «tonta» sino «a liar and a hypocrite»-. ${ }^{16}$ Ambos supervisan milimétricamente la educación de la joven, a la que mantienen alejada de cualquier otra influencia. Sus únicas compañeras de recreo son la hija de Conroy y su medio hermana mayor, Feodora, hasta que en 1830 la duquesa de Kent la presenta en público. Las intenciones de ambos radican en que la joven delegue en su madre como regente hasta cumplir veintiún años, regencia que sería ejercida de facto por Conroy. Es el convencimiento obsesivo de un dudoso y no reconocido parentesco de sangre con la realeza ${ }^{17}$ aquello que mueve al irlandés a forzar para sí mismo una posición de poder en la corte -concretamente, el cargo de secretario privado de la futura monarca-.

The Young Victoria incide en la tensa relación de Victoria con la duquesa y representa el impenitente alejamiento al que la reina sometió a su madre y Conroy una vez subió al trono. El filme muestra brevemente, por ejemplo, un suceso acaecido en 1835, cuando Victoria cae enferma a los dieciséis años ${ }^{18}$ y los dos intentan aprovechar su estado de debilidad para «arrancarle la promesa escrita de que nombrará a Conroy como su "secretario privado" el día de su ascensión al trono. Conroy le ha llevado a la cama un papel y un plumero, pero la princesa, sujeta por Lehzen, se niega a tal propósito». ${ }^{19}$ La baronesa Lehzen, aya de Victoria -enfrentada también a la duquesa y su secretario-. la apoya en su resistencia y finalmente, cuando el rey Guillermo IV fallece, esta sube al trono con dieciocho años. Un significativo encuadre, en este sentido, muestra a Victoria empequeñecida, desenfocada, en segundo término y a contraluz,

15. Incapaz de hacer frente a las deudas del duque de Kent cuando este fallece -ni siquiera con la ayuda de su hermano, el rey Leopoldo de Bélgica-, la duquesa queda a merced de sus cuñados ingleses, los reyes Jorge IV y Guillermo IV, a los cuales abiertamente desagrada y viceversa, en un país cuya lengua prácticamente no habla y cuyo parlamento es contrario a mantenerla económicamente, siendo todavía Victoria la cuarta en la línea sucesoria al trono.

16. Giles St. Aubyn: Queen Victoria: A Portrait, Siclair Stevenson, London, 1991, p. 72.

17. Concretamente, sucumbió al rumor de que su esposa era el fruto de una relación entre su madre y el duque de Kent, y por tanto medio hermana de Victoria -hipótesis hoy descartada historiográficamente-. Katherine Hudson: A Royal Conflict: Sir John Conroy and the Young Victoria, Hodder and Stoughton, London, 1994.

18. A consecuencia, en parte, de los tours o «royal progresses» establecidos por Conroy y la duquesa para promocionar su imagen, que comenzaron en la década de 1830 y consiguieron el propósito de aumentar su propularidad.

19. Philippe Alexandre y BÉAtrix D’Aulnoit: Victoria (1819-1901). Reina y emperatriz, Edhasa, Barcelona, 2001, p. 73. 
mientras en el primero aparece la mano de Conroy sobre un mapa, junto con las de la duquesa y su dama Lady Flora Hastings, connotando su voluntad estratégica y la (todavía) vulnerabilidad de la joven frente a sus tutores (fig. 4).

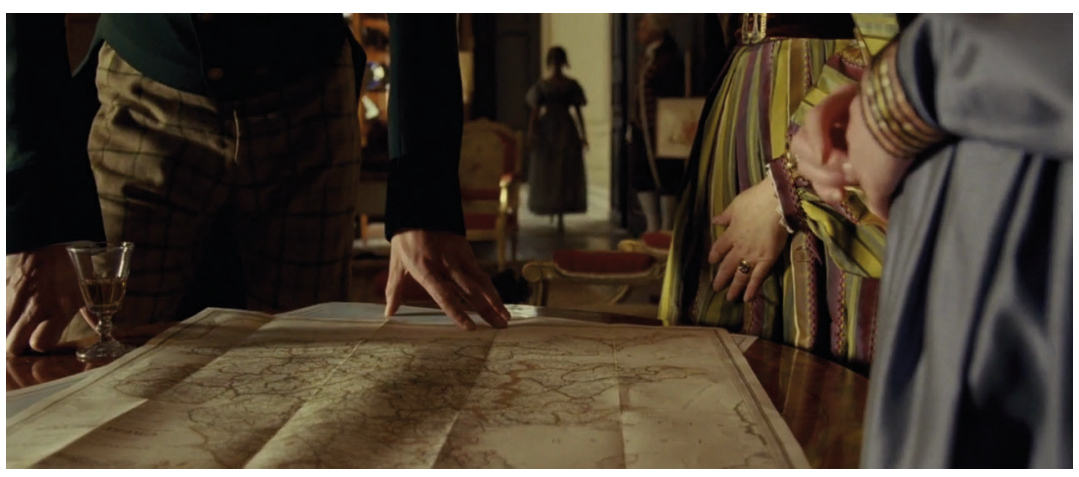

Fig. 4. Victoria empequeñecida en The Young Victoria, 2009.

La distancia entre madre e hija toma consistencia espacial en el filme, que las dispone lo más alejadas posible dentro de la estancia que comparten para dormir (fig. 5).

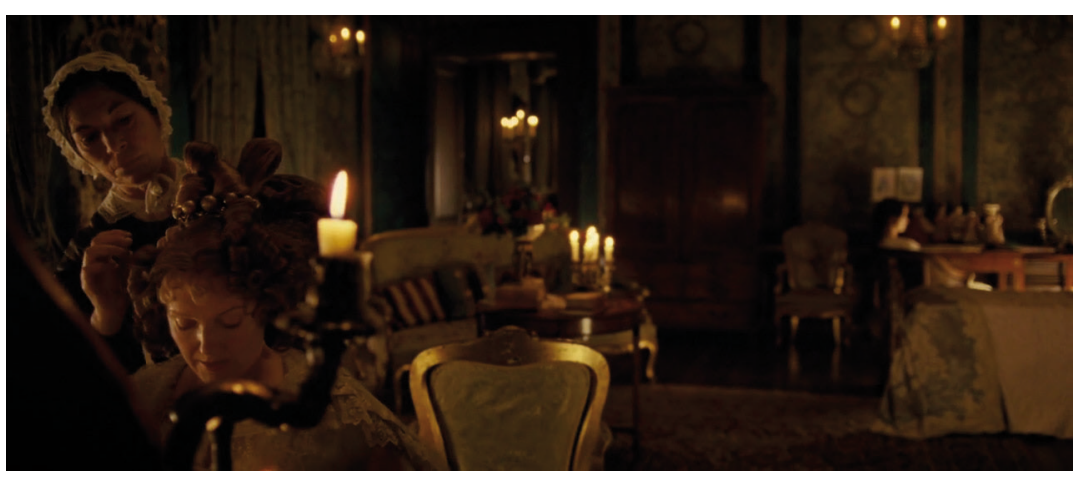

Fig. 5. La duquesa de Kent y Victoria en The Young Victoria, 2009.

Su conversación se engarza desde la simulación de planos-contraplanos sostenidos desde espejos, los cuales redoblan la distancia entre las mujeres. En permanente desacuerdo, cuando sus miradas se encuentran, lo hacen desde la máscara del reflejo que media entre ellas, y no directamente. De este modo, el recurso del plano-contraplano que convencionalmente sirve para vincular -paradójicamente, 
mediante corte- se pone al servicio de subrayar el alejamiento entre las dos, lo difícil de soslayar los dispositivos que hacen de barrera entre ambas (fig. 6 y fig. 7).

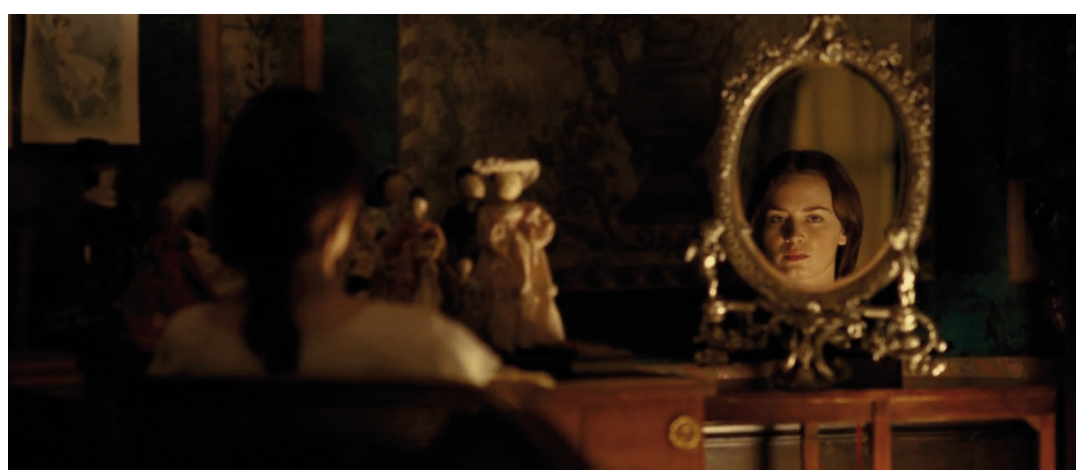

Fig. 6. Victoria mira a su madre desde el espejo.

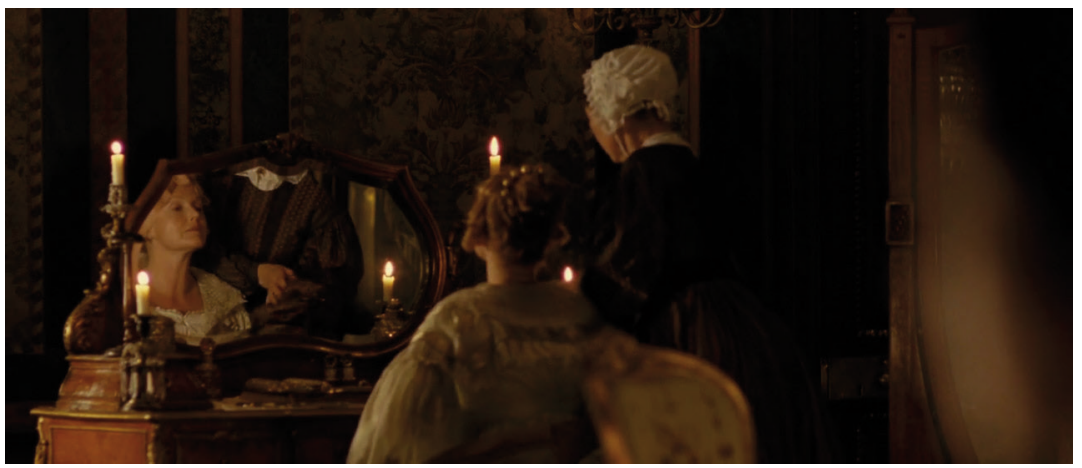

Fig. 7. Contraplano de la figura anterior.

La separación física y sentimental entre ambas crece ${ }^{20}$ hasta que Victoria da a luz a su primera hija y Alberto se esfuerza en aproximarlas, pues las primeras medidas que Victoria toma como reina van dirigidas a deshacerse del Kensington System: dispone aposentos separados para ella y su madre, exige una hora para sí misma cada día y gestiona el alejamiento de Conroy. Antes, empero,

20. Las exigencias de la duquesa no cesarían con la subida al trono de su hija. Sin embargo, todas ellas se verían rechazadas. Victoria le negaría el título de «reina madre», establecería estancias para que durmieran y comieran separadas, buscaría consejo en otros (su primer ministro Lord Melbourne, Lehzen o el rey Leopoldo) y permitiría a la duquesa verla, solamente, bajo cita y en recepciones oficiales. Antes de que el príncipe Alberto mediara entre ambas para reconciliarlas, la duquesa viviría todavía más alejada de la corte de su hija, en Clarens House, en St. James, y en Frogmore Lodge en Windsor. Dulcie Ashdown: Queen Victoria's Mother, Robert Hale, London, 1974. 
tiene lugar otro célebre episodio en el que diversas imágenes -de riquísima y preciosista puesta en escena- se componen disponiendo la mencionada distancia, que se traslada a lo público con ocasión de la celebración del cumpleaños del rey Guillermo IV en 1836 (fig. 8 y fig. 9). El banquete es históricamente recordado por cómo el rey -de rudos modales- declara su angustioso deseo de llegar a vivir otros nueve meses, tiempo suficiente para que Victoria obtenga la mayoría de edad y no haya, por tanto, posibilidad alguna de regencia.

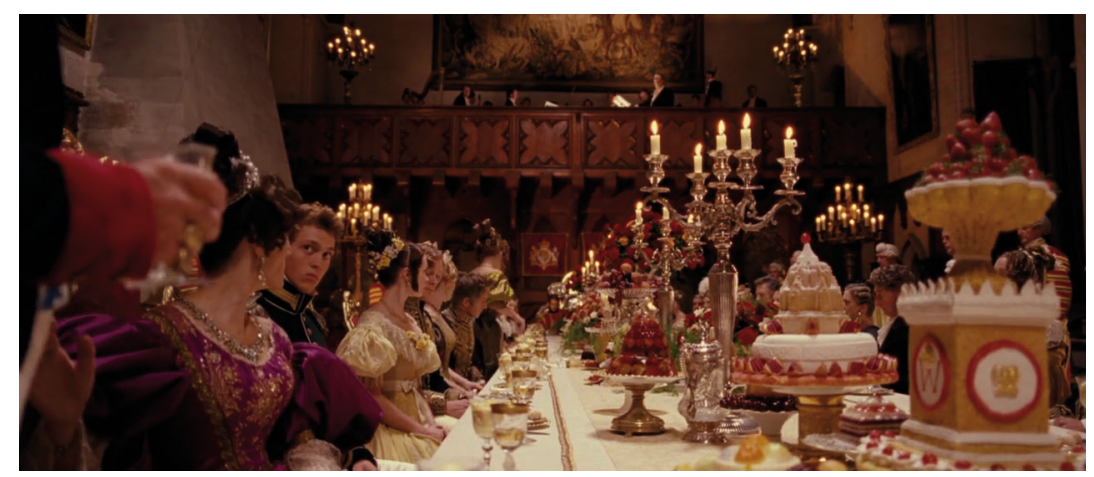

Fig. 8. La duquesa se marcha airada del banquete.

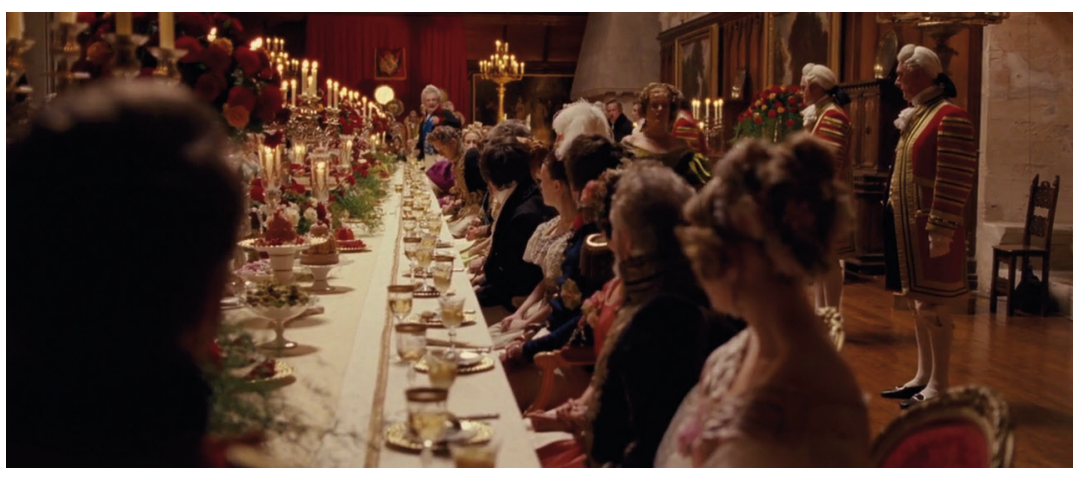

Fig. 9. Guillermo IV grita sus reproches señalando a la duquesa.

Una composición simétrica enfrenta a la duquesa -a la izquierda- y al rey y su sobrina -a la derecha- mientras este le recrimina que esté ocupando en Kensington habitaciones que él reservó para sí mismo, con los escorzos desenfocados de los asistentes delante. Larguísimos puntos de fuga compuestos por la mesa del banquete y los invitados sentados a la misma en sendas hileras muestran al rey, de pie, profiriendo su discurso contra su cuñada por mantener cautiva a su sobrina. A ambos extremos, el indignado soberano la señala con el dedo hasta que, avergonzada, la duquesa se marcha airada. 
Un travelling circular sigue y rodea a Victoria cuando, habiendo sido informada de la muerte del rey, recibe sola a los dignatarios ${ }^{21}$ procedentes del lecho de muerte de aquel, en el castillo de Windsor, en su sala de estar. La iluminación blanca aclara su piel, que destaca entre el negro del vestido, cuando Victoria ejerce el primero de sus actos con independencia de supervisión materna. El filme sitúa en sus labios las palabras que escribió en su diario respecto a su solemne deber: «Since it has pleased Providence to place me in this station, I shall do my utmost to fulfill my duty towards my country; I am very young and perhaps in many, though not in all things, inexperienced, but I am sure, that very few have more real good and more real desire to do what is fit and right than I have». ${ }^{22}$

\section{LOS BAILES}

Una de las costumbres de la vida de la reina que cambia con su matrimonio, en virtud de la gran influencia que el príncipe Alberto imprime sobre ella, es su constante participación en bailes y fiestas, su gusto por trasnochar y permanecer por la mañana largo tiempo en la cama. Tal influencia proveniente del príncipe consorte -como prácticamente todas las que conforman el carácter puritano adoptado por la reina y designado en conjunto bajo el amplio paraguas de lo victoriano- es ignorada por The Young Victoria, que destaca, simplemente, la capacidad práctica y ahorradora de Alberto en la reorganización de los recursos de palacio.

La danza en pareja, como sucede constantemente en melodramas de época, es dispuesta en tanto episodio nuclear en la medida en que la aproximación física de los enamorados da lugar a una complicidad que les confirma -y traslada al espectador- una atracción o enamoramiento recíprocos. La puesta en escena y los movimientos de cámara subrayan y enfatizan la relevancia de esta. Un suave cambio de distancia focal aleja a Victoria, que acaba de entrar en el gran salón de baile con sus damas, del resto de personajes que forman un friso tras ella. Un fantasioso travelling la transporta suavemente, como flotando, al despejado centro de la estancia donde la espera el príncipe Coburgo.

El imposible desplazamiento avisa de la focalización del relato en la percepción subjetiva de los personajes, embelesados en ellos mismos y abstraídos de la -complacida- realidad que les observa y circunda (fig. 10 y fig. 11). Así lo disponen los planos cercanos a sus rostros y travellings que giran sobre las propias vueltas de los danzantes. Ambos dejan caer cuidadosamente sus manos, enlazadas en círculo sobre sus cabezas. El descendimiento de los brazos se muestra en repetidas ocasiones desde diferentes puntos de vista, de modo que

21. El arzobispo de Canterbury, lord Conyngham, y el lord Chamberlain.

22. A. C. Benson y Escher Vicount (eds.): Letters of Queen Victoria 1837-1861, John Murray, London, 1911. 
el énfasis en la fascinación del enamoramiento de la pareja prevalece sobre la continuidad temporal del raccord, rota por la repetición del gesto.

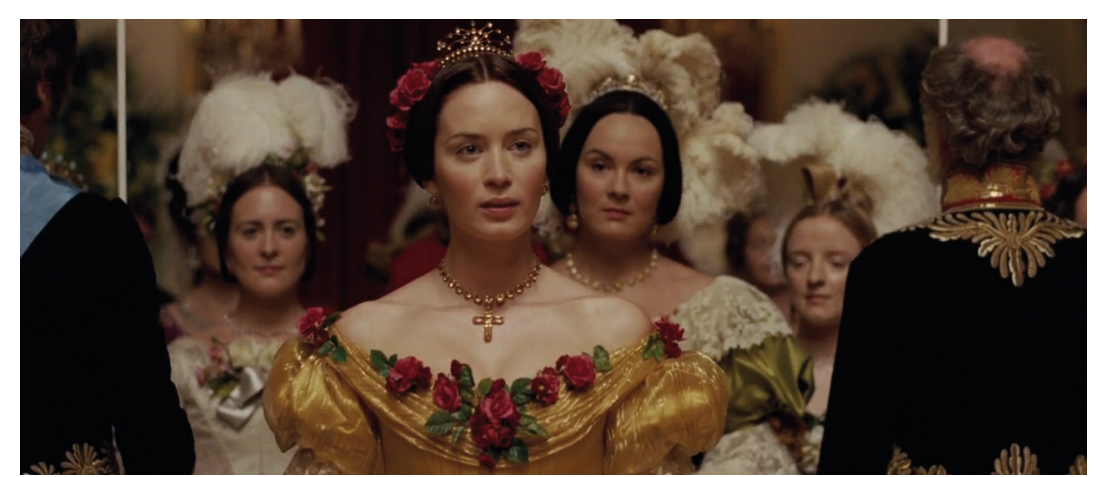

Fig. 10. Victoria fija su mirada en Alberto.

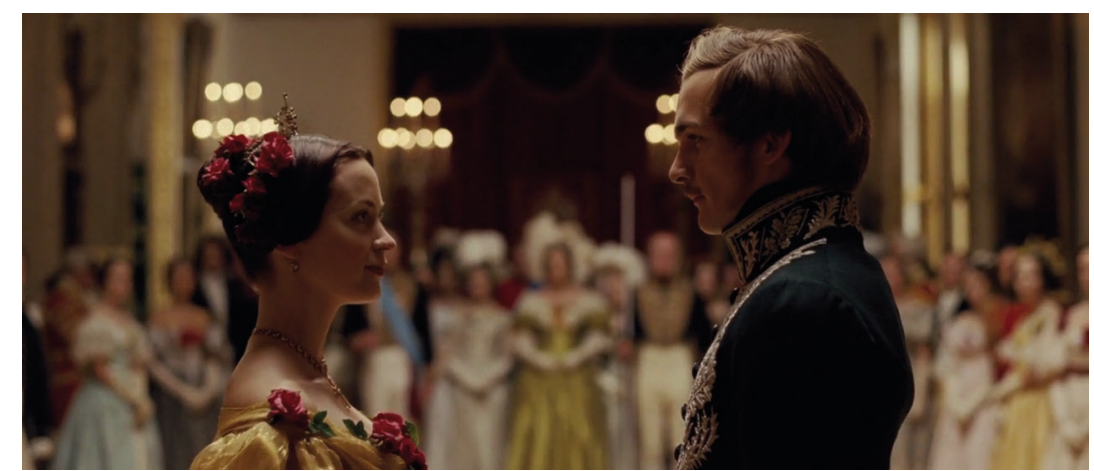

Fig. 11. Victoria y Alberto comparten plano tras el travelling que la desliza junto a él.

Las escenas de baile representan también en los dos siguientes filmes momentos de especial -y poco frecuente- gozo en la madurez y vejez de Victoria. Pero antes de acudir a ellas mencionaremos, por último, que el montaje de The Young Victoria concede una importancia casi política al baile cuando, por montaje paralelo, representa el doble aprendizaje del príncipe Alberto, que practica el vals -Victoria lamentó en su primer encuentro que no lo conociera- mientras es entrenado en el reconocimiento de los protagonistas políticos fundamentales de Inglaterra, alternado con la llegada de Victoria y algunos otros invitados a Windsor - precisamente, los que Alberto va mencionando, como lord Melbourne o sir Robert Peel- para la celebración del aniversario real. Se desliza, así, la indisoluble vinculación del cortejo del príncipe con la estrategia política de la alianza matrimonial, la cual Alberto no cuestiona. Sin 
embargo, son otros personajes los representados como estratégicamente interesados en este, mientras que en Alberto, simplemente, parecen coincidir felizmente tales intereses con su inclinación sentimental hacia su prima hermana Victoria.

Los diarios de Victoria ${ }^{23}$ y las crónicas de la época atestiguan el gusto e incluso la gracia de la reina para el baile -aun teniendo una figura cada vez más oronda-. Tanto antes de casarse como después de ser madre, la pareja real gustaba de bailar en privado y en público. ${ }^{24}$ Sin embargo, fallecido prematuramente el príncipe en 1861, el baile fue erradicado de la corte como tantas otras celebraciones y actividades cotidianas eclipsadas por el abrumador ritual de duelo al que Victoria sometió a la familia real y sus sirvientes. Con todo, tal era el amor de la reina por las danzas escocesas, indesligable de sus recuerdos en Balmoral con Alberto, que la celebración de bailes allí persistió en su viudez para el disgusto de damas y caballeros -quejosos del aspecto sudoroso y ebrio de los highlanders - que debían atender a los eventos, muchas veces celebrados al aire libre independientemente del clima. ${ }^{25}$

Aunque el retorno de la reina al baile se acentuó con las celebraciones de los jubileos que trajeron consigo la vuelta de recepciones, Mrs. Brown representa una de esas veladas trasladándola años atrás, a 1866, y convirtiéndola en la escena que, decididamente, apunta en el filme a la paulatina disminución de la pesadumbre, aislamiento e inquebrantable pena de la soberana viuda. El tratamiento cinematográfico que recibe el baile en Mrs. Brown difiere radicalmente del vals mencionado con anterioridad. Es desde un picado elevado que se muestra el rústico salón al fondo del cual violines y gaitas tocan mientras la familia real y sus acompañantes danzan (fig. 12).

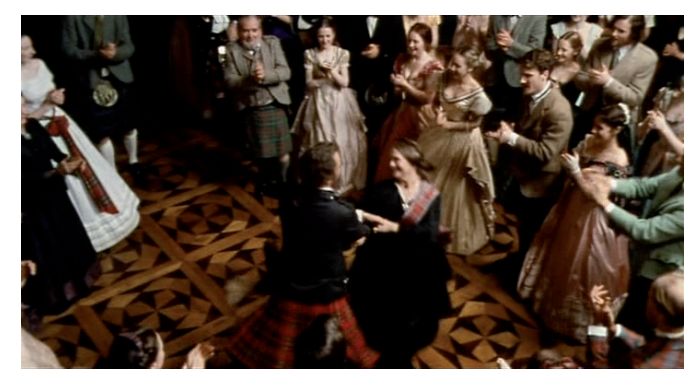

Fig. 12. Plano picado de la reina bailando con John Brown en Mrs. Brown, 1997.

23. Viscount Esher (ed.): The Training of a Sovereign, John Murray, London, 1914.

24. Algunos de los bailes formales que ofrecieron en Buckingham Palace -como el Plantagenet Ball de 1842, el Georgian Ball de 1845 o el Restoration Ball de 1851- fueron tildados de ostentosos y extravagantes por ser celebrados en tiempos de reivindicaciones cartistas y depresión económica.

25. E. E. P. TisDalL: Queen's Victoria's Private Life, Jarrolds, London, 1961 
Un travelling se aproxima a la reina cuando pasa a bailar con Brown mientras el resto marca el folclórico ritmo escocés con palmas. Los primeros planos de la reina, que respira agitada una vez la música cesa, la muestran prudentemente sonriente pero también abiertamente complacida (fig. 13). Como en el anterior filme, se intercalan planos de Bertie (1841-1910), heredero al trono a quien desagrada en particular Brown, su esposa Alexandra, las damas de compañía de la reina y los miembros del servicio de más responsabilidad, que si bien parecían disfrutar bailando, miran con severidad a la reina. En cualquier caso, la cámara no envuelve los movimientos de la pareja ni se detiene en sus expresiones; tampoco la iluminación ni el ritmo del montaje califican el momento en términos románticos, aunque el gesto sonriente de Victoria, su respiración y su cuerpo en movimiento marcan una diferencia respecto a su comportamiento anterior (fig. 14).

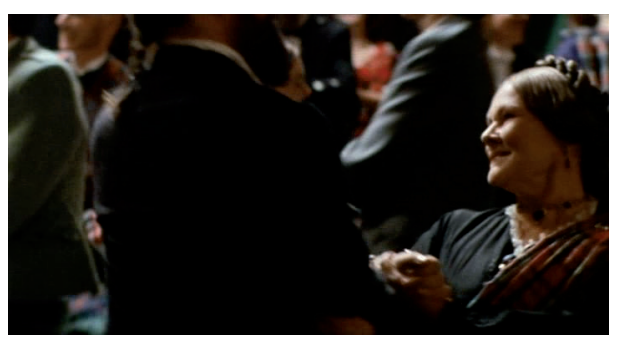

Fig. 13. Un travelling atiende el baile de la reina con Brown.

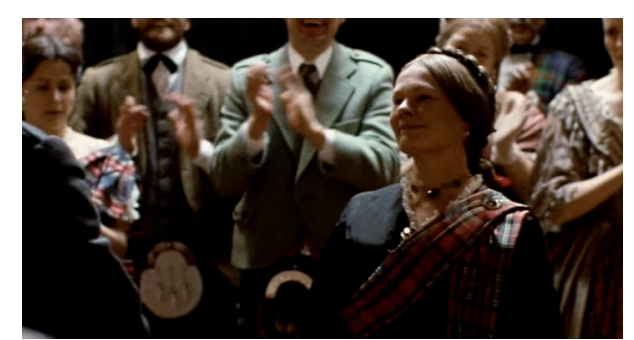

Fig. 14. Victoria sonríe aplaudida por la corte.

Si bien la estrecha relación entre John Brown y la reina y los privilegios que esta le otorgó despertaron recelo y habladurías entre los allegados de Victoria, la lealtad del escocés hacia ella nunca se puso en duda. En cambio, el que la reina consideraría su munshi («maestro»), su sirviente indio Abdul Karim (1863-1909), fue objeto de sospecha, acusaciones e incluso investigaciones del servicio de inteligencia británico desde que pasara a formar parte de su 
personal más cercano. Victoria jamás reconoció públicamente ninguna de las acusaciones hacia el munshi, cuya base tenía una indudable parte de común prejuicio racista. ${ }^{26}$ No obstante, en Victoria $\mathcal{E}$ Abdul son dos los momentos en los que la reina se siente defraudada, herida y engañada por Karim, y el primero de ellos precisamente tiene lugar tras la última de las escenas de baile que mencionaremos, que resulta ser la más íntima, por diferentes motivos, de todas ellas.

Con una mayor capacidad de ironía, crítica hacia la nobleza británica y matices narrativos, el filme de Stephen Frears se abstiene de juzgar al munshi representándolo como un ser vital, parlanchín, que trata prudente y respetuosamente a los cortesanos hostiles hacia él, moviéndose entre ellos con la naturalidad que le permite su posición privilegiada. En una decadente velada florentina a la que acude un afónico y caricaturesco Puccini, la reina, a instancias del munshi, entona penosamente la jovial canción I'm Called Little Buttercup, de la ópera cómica H. M. S. Pinafore o The Lass that Loved a Sailor (de Arthur Sullivan y libreto de W. S. Gilbert) mientras la corte exasperada entorna los ojos y Bertie la acompaña torpemente al piano. Animada tras el aplauso que corta su actuación, la reina celebra el brindis a su salud y tararea la melodía casi de forma infantil mientras camina dando pequeños saltitos, con el munshi, bajo un porche porticado. Enternecida y, en sus palabras, feliz como hacía años que no lo era, acepta la invitación de su sirviente a bailar. La cámara se les aproxima progresivamente mientras él le va confesando que al principio la temía pero resultó ser una mujer muy amable con él (fig. 15 y fig. 16).

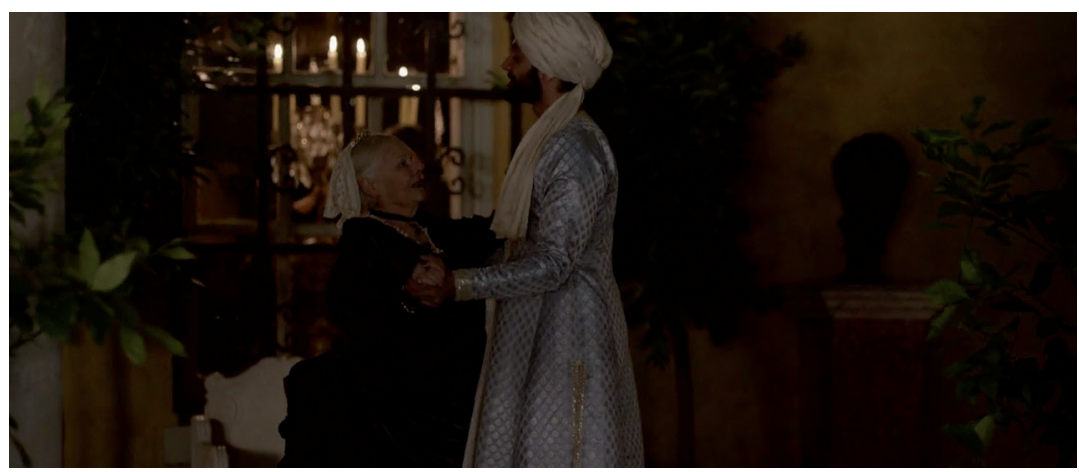

Fig. 15. La reina anciana baila con el munshi en Victoria y Abdul, 2015.

26. RAPPAPORT, Queen Victoria, p. 259. 


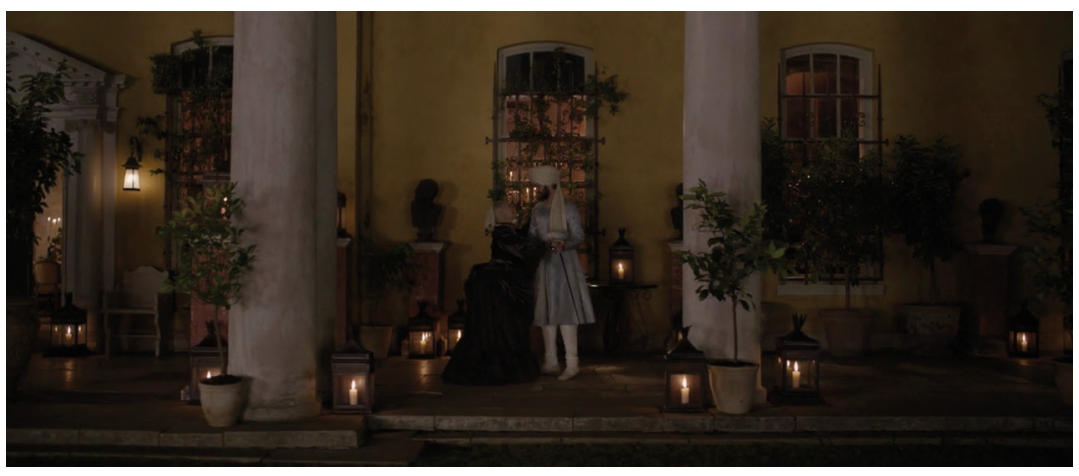

Fig. 16. La cámara sigue el baile.

Mientras les sigue en su baile, el eje de la cámara tuerce ligera pero significativamente el plano cuando Karim empieza a decirle que sabe que es mucho mayor que él, la reina de Inglaterra y la emperatriz de la India, mientras que él es un humilde munshi (fig. 17). El cerrado contraplano de la reina la muestra emocionada, escuchando la declaración casi amorosa de su sirviente. No obstante, su expresión muta hacia el desconcierto cuando Karim -desde un primer plano todavía más cerrado- le revela que la considera la mujer más especial de su vida, incluso más que su esposa. La reina, atónita puesto que desconocía -como el espectador- que estuviera casado, le insta a ir a buscar a su esposa inmediatamente a la India (fig. 17 a 20).

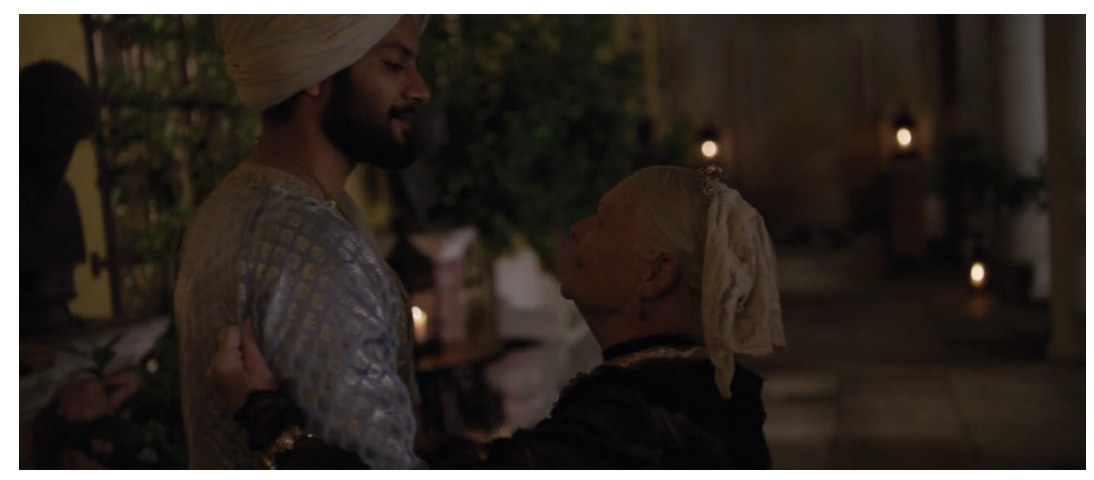

Fig. 17. El eje del plano se tuerce ligeramente mientras bailan. 


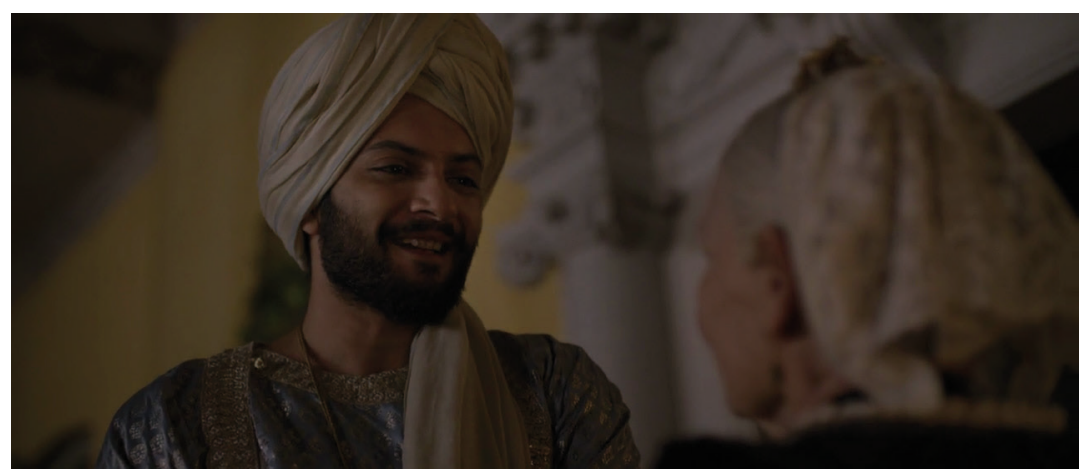

Fig. 18. Karim, en contrapicado, expresa su afecto por la reina.

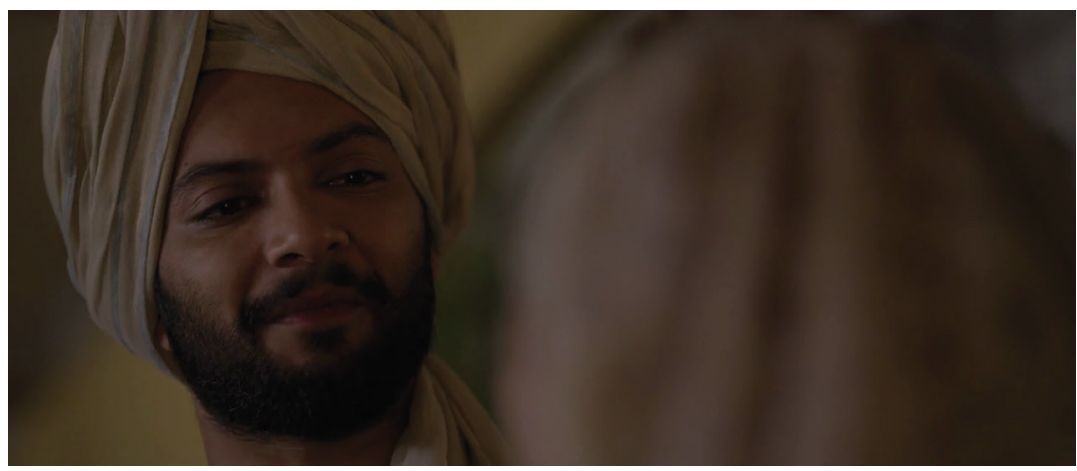

Fig. 19. El plano se cierra sobre el rostro del munshi.

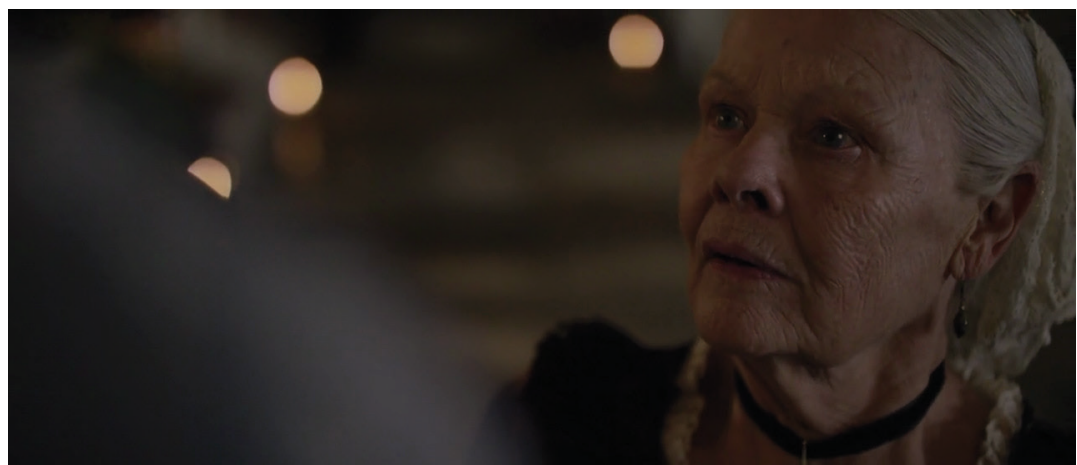

Fig. 20. Primer plano de la conmoción de Victoria.

El segundo y más dramático reproche tiene lugar cuando la reina, defendiendo al munshi frente a la corte, hace el ridículo frente a los argumentos de Bertie, el Dr. Reid y su secretario privado, que destacan el papel musulmán en el arranque de 
la Rebelión India de 1858-1859, dejando a la reina sin respuesta. Sintiéndose confundida y humillada por culpa del munshi, la reina reprocha desolada su engaño al joven. En una galería interior del palacio de Osborne, más oscura e iluminada de forma mucho más fría que la anterior, enumera todo lo que ha hecho por él pese a la oposición del personal de su casa y destaca que incluso dejó pasar que no le dijera que estaba casado. Aunque Karim se disculpa e intenta matizar su explicación, Victoria, dolida, le dice que deberá regresar a casa, y que le echará de menos (fig. 21).

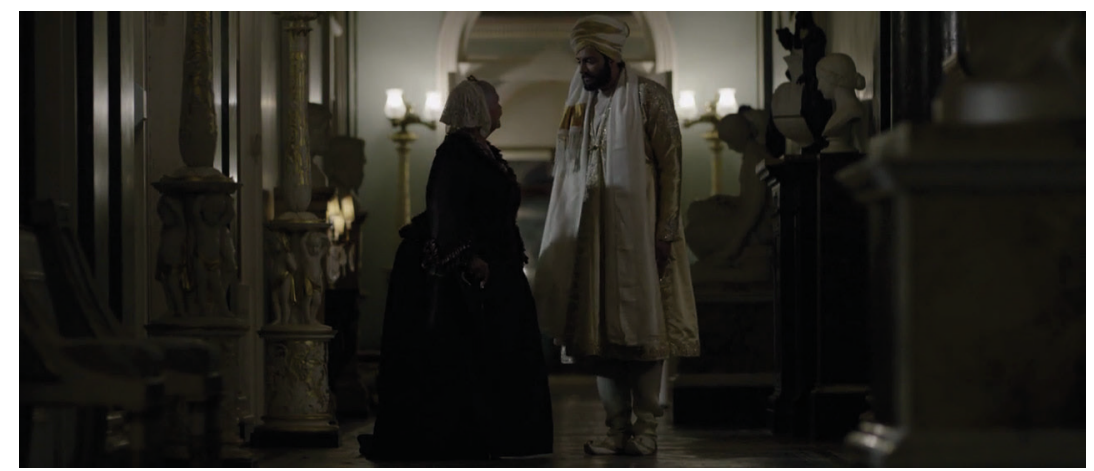

Fig. 21. La colorimetría se vuelve grisácea con el disgusto de Victoria.

El sonido de la tormenta que cae fuera de campo acompaña su separación, mientras entra también una melancólica banda sonora extradiegética. Dos planos generales subrayan mediante la distancia focal la separación física entre ambos. La reina, envejecida súbitamente de nuevo, camina encorvada apoyada sobre su bastón, mientras Karim, quieto y lloroso, se gira viéndola marchar. Un primer plano mantenido por un discreto travelling la acompaña mientras, fatigosa y ajena a que la siguen detrás algunos miembros de su casa, camina hacia sus aposentos (fig. 22 y fig. 23).

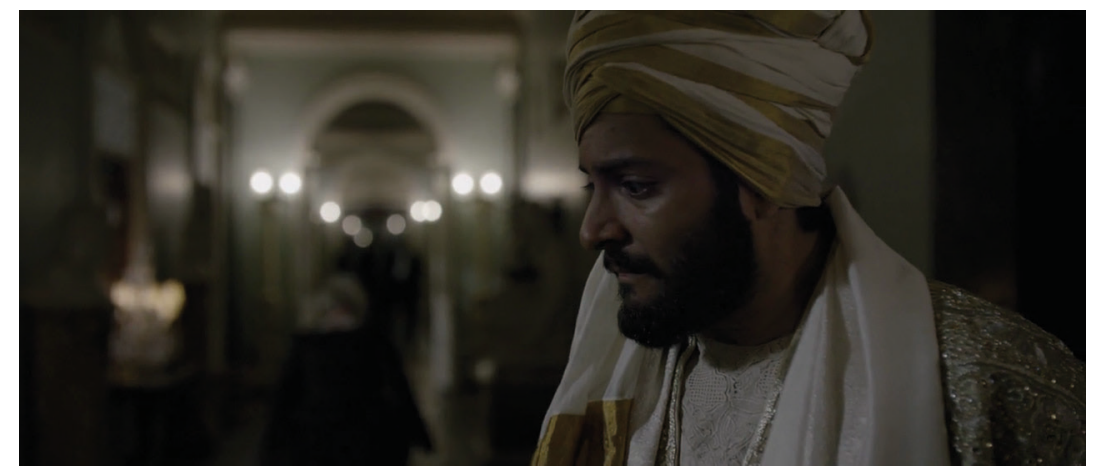

Fig. 22. Victoria se aleja, en segundo término. 


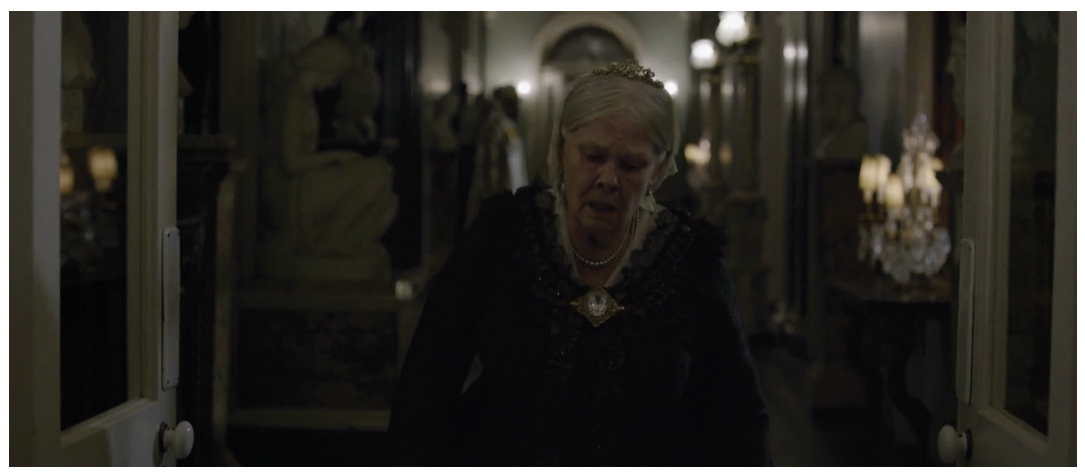

Fig. 23. Contraplano de la figura anterior.

La fragilidad emocional, más que física, de Victoria es mostrada por la enunciación en este punto del filme más agudamente que en ningún otro cuando, vencida, responde sin girarse a las buenas noches de su hijo, satisfecho como la pequeña camarilla que ha observado la escena escondida (fig. 24 y fig. 25).

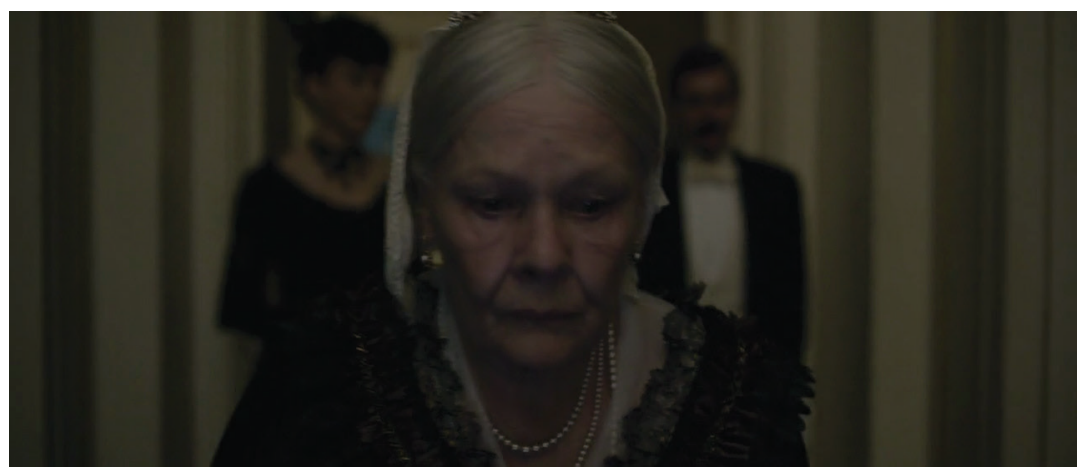

Fig. 24. La reina se retira vigilada por la camarilla.

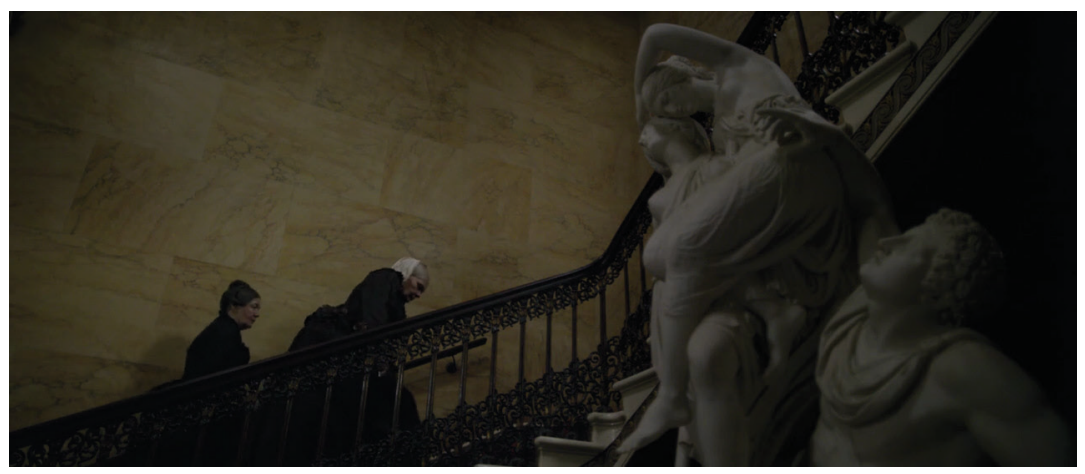

Fig. 25. Contrapicado de la reina subiendo costosamente las escaleras. 
Un contrapicado acentúa lo empinado de las escaleras que sube costosamente, mientras la banda sonora enfatiza su pesar y envilece la animosidad de sus familiares y allegados.

\section{El PRÍNCIPE y EL DUELO}

Los dos bailes anteriores guardaban una relación con el príncipe Alberto, el primero de forma directa y el segundo evocando su memoria desde Escocia. Este tercero desemboca de nuevo en la añoranza y patológico duelo hacia el príncipe cuando Victoria, desprovista de sus atributos reales y frente a un espejo que le devuelve la imagen de una anciana melancólica, levanta la mirada llorosa desde su tocador hacia la fotografía del príncipe que cuelga en la pared -mientras la banda sonora introduce ligeras notas más agudas-. Como si hubiera dialogado con la fotografía al mirarla, la reina suspira y llama a su ayudante (figs. 26 a 29). Bajo la lluvia nocturna, ambas acuden en carruaje para que la reina, en virtud de la devoción que su sirviente le ha mostrado, le permita quedarse.

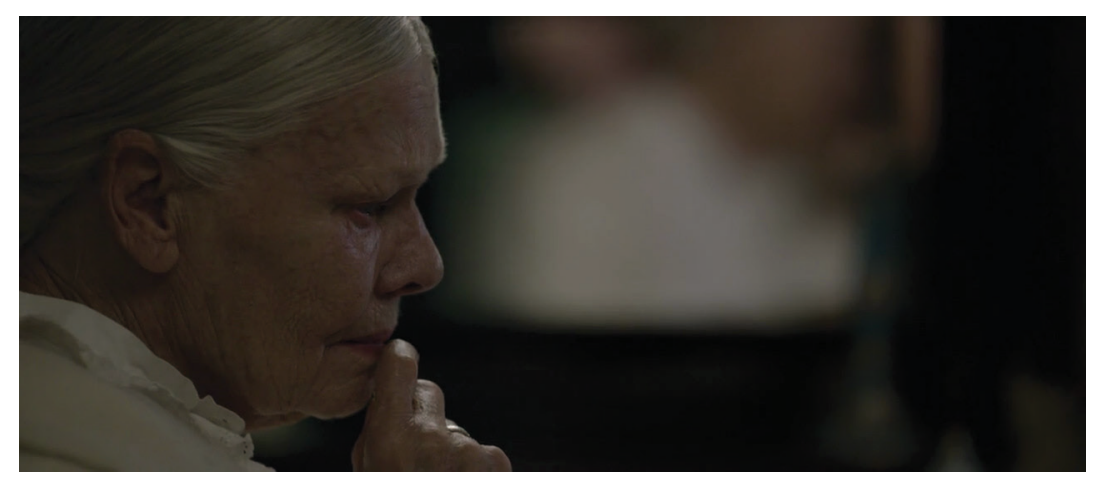

Fig. 26. Primerísimo primer plano de la reina, llorosa.

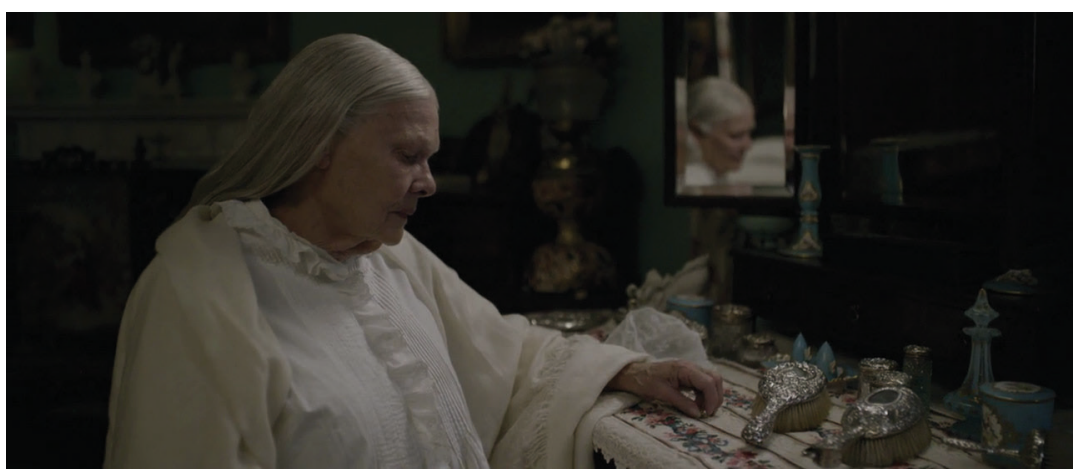

Fig. 27. Un plano más amplio muestra su reflejo en el espejo del tocador. 


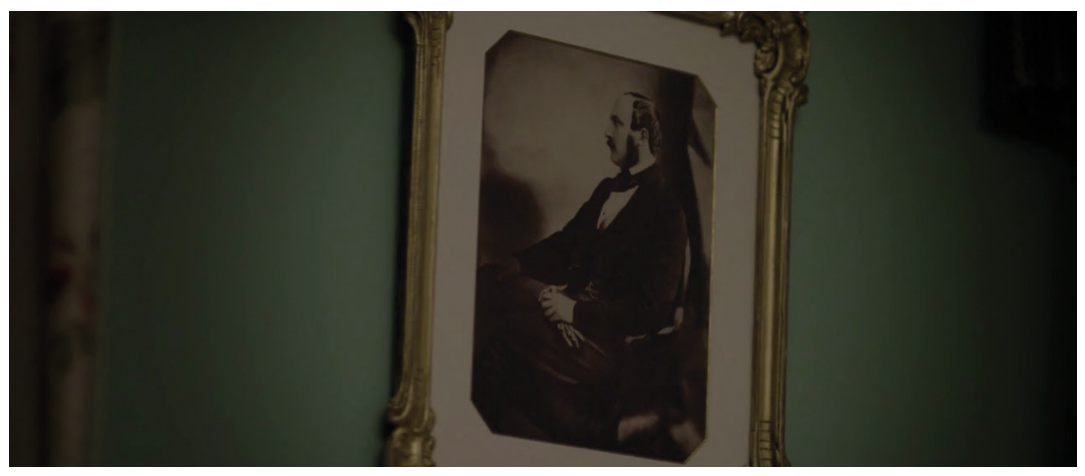

Fig. 28. Plano subjetivo del retrato del príncipe Alberto.

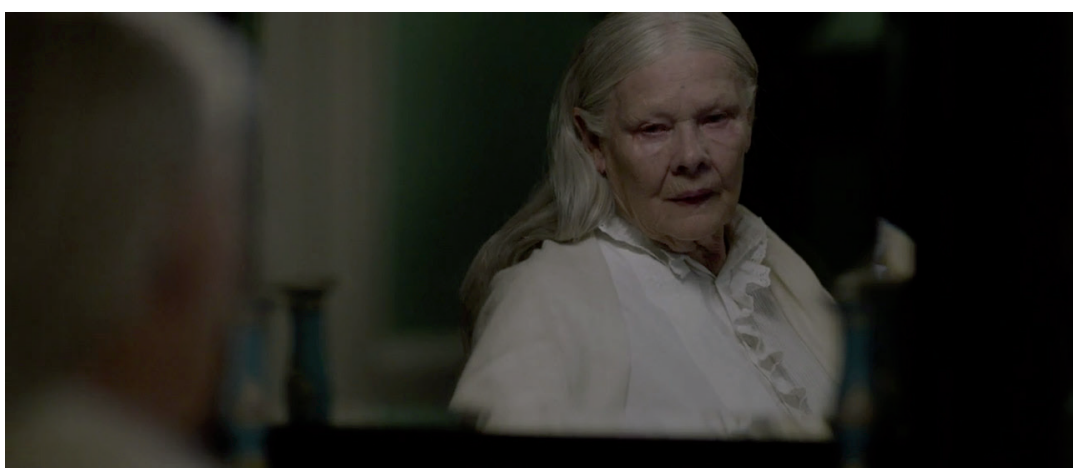

Fig. 29. Victoria se mira en el espejo.

La huella del príncipe Alberto en Victoria sería tan profunda que, una vez viuda, trataría de mantener durante toda su vida, tanto privada como política, los estándares morales y decisiones que creía que Alberto hubiera tomado en su lugar. Con ello, defendió como sagrados los valores que guiaban la conducta del príncipe consorte: la ética del esfuerzo en el trabajo, la conciencia del deber, el orgullo cívico, la solemnidad en sus propósitos, la austeridad o la intachable rectitud moral que han pasado a la historia como parte importante de la moral victoriana.

The Young Victoria invierte buena parte de su metraje en representar los primeros encuentros entre la joven y muestra que Alberto fue prácticamente desde que nació el candidato que el tío de ambos, Leopoldo, proponía para el matrimonio de Victoria - decisión que la molesta profundamente-. El filme también deja entrever, suavizado, el fracaso del primer encuentro entre ambos. Si bien expone la intensa atracción física entre $\operatorname{los} \operatorname{dos}^{27}$ y la adoración

27. Alexandre y D’Aulnoit, Victoria (1819-1901), p. 128. 
que ella le profiere mediante el explícito lenguaje visual del melodrama, son más los aspectos que se omiten de la relación entre ellos, como la declinación del príncipe de las diversiones mundanas que entretienen a Victoria, o su preferencia por la compañía de personalidades cultas -intelectuales, científicos, literatos- ante los que la joven se siente en inferioridad de condiciones. Una vez casados, no hay apenas rastro de las constantes discusiones domésticas, la irascibilidad de la reina o su aborrecimiento del embarazo y la maternidad. ${ }^{28}$ La cinta deja de lado el hecho de que la cultura y sensibilidad política de Victoria se refinaron bajo la supervisión de Alberto, si bien muestra en las reflexiones que le hace hacia el primer ministro Sir Robert Peel su esfuerzo en inculcarle la imparcialidad política que se esperaba de una monarquía constitucional. ${ }^{29}$ En aras de la construcción de un personaje femenino independiente y fuerte, como de la predilección por la historia sentimental, queda fuera de campo el hecho de que no hubiera una sola decisión que Victoria no consultara a su marido: ${ }^{30}$ "Era Alberto quien por la mañana aprobaba la elección de su vestido y de su sombrero, era Alberto quien le dictaba todos y cada uno de sus discursos y cada carta que escribía, era Alberto quien le explicaba cómo debía posar para los pintores y los escultores y así legar a la posteridad una imagen de la monarquía digna de admiración». ${ }^{31}$ El cine se resiste a explorar la figura del príncipe consorte, dejándolo en segundo lugar o fuera de campo, del mismo modo que la sociedad británica lo miró con recelo, hasta pasada su muerte, por el doble pecado de ser extranjero y alemán -que se burlaría apelando a él como «Albert der King»-. Ni su papel en la educación de la reina ni su influencia política ni su patronazgo de las artes y la investigación científica

28. Cristopher Hibbert: Queen Victoria, a Personal History, Harper Collins, London, 2000; YvonNE WARD: «The Womanly Garb of Queen Victoria's Early Motherhood, 1849-1842», en Women's History Review, 8 (2), 1999, pp. 277-294.

29. La imagen política de la reina se había visto dañada, en este sentido, con la Crisis de las Damas de Cámara de 1839. Ante el inminente cambio de gobierno whig, encabezado por el primer ministro lord Melbourne, adorado por Victoria, la reina se había negado al requerimiento de sir Robert Peel, que debía formar un gobierno tory, de que sustituyera algunas de sus primeras damas whigs por esposas de tories, entendido como una muestra de apoyo al nuevo gobierno. Alegando que no había precedentes que la obligaran a ello, y que la política no tenía relación con sus damas de compañía, Victoria no cedió ante Peel que, indignado, se retiró. En lo que sería visto como un acto caprichoso y prácticamente inconstitucional, Victoria restauró a lord Melbourne en el cargo y durante un tiempo consiguió retenerle a su lado, manteniendo la rutina de charlas y largos paseos a caballo con su admirado y cercano mentor, cuyo gobierno se desmoronaría definitivamente en 1841. Para entonces, Alberto había ocupado ya el lugar de «lord M» en el corazón y la enseñanza de la reina. La crisis ha sido reinterpretada recientemente en clave de género: «Far from being an insignificant political tantrum thrown by an inexperienced teenaged Queen [...] the true legacy of the Bedchamber Crisis consists of the ironic combination of a victory for female kingship won by an assertion of the political insignificance of women». ChARLEs BEEM: The Lioness Roared: The Problems of Female Rule in English History, Palgrave Macmillan, New York, 2008, p. 144.

30. El diarista de la corte, Charles Grenvil, llegó a escribir en 1845: «They are one person, and as He likes and She dislikes busines, is obvious that while she has the title he is really discharging the functions of the Sovereign». Lytton Strachey y Roger Fulford (eds.): The Grenville Memoirs, Macmillan, London, 1938, p. 257.

31. Alexandre y D’Aulnoit, Victoria (1819-1901), p. 331. 
entran en campo en los filmes que estudiamos aquí. ${ }^{32}$ La melancólica soledad de Alberto, insatisfecho con sus tareas domésticas, y su dificultad para encontrar un espacio propio en el que volcar sus capacidades intelectuales, políticas y culturales son soslayadas para saltar de su papel como apuesto pretendiente de la heredera a su imagen como el «santo de vidriera» ${ }^{33}$ en el que su viuda le convirtió, ganándose el apodo de la Viuda de Windsor.

Cuando Alberto consideró poco saludable la excesiva e histérica aflicción de Victoria ante la muerte de su madre ${ }^{34}$ poco podía suponer que, en apenas unos meses, su esposa se sumiría en un abismo mucho más profundo que marcaría extravagantemente su comportamiento $-y$, a la fuerza, el de su familiadurante el resto de su vida.

De las proporciones épicas del duelo de Victoria quedan, en Mrs. Brown y Victoria $\mathcal{E} A b d u l$, reminiscencias como las mencionadas fotografías y cuadros del príncipe repartidos por todas las residencias reales. Sin embargo, puesto que empiezan in medias res, el tiempo ha convertido en rutina y materializado en mementos los estallidos nerviosos de Victoria. Habiendo destacado ya un par de cuestiones respecto al duelo en Victoria $\mathcal{E}$ Abdul, mencionaremos alguna de las presentes en Mrs. Brown -siendo el propio abatimiento y malhumor de la reina su signo más evidente-. El impenetrable duelo de la reina es lo que precipita la llegada de su coprotagonista, John Brown, y la relevancia del mismo abre el filme. Un montaje paralelo entrelaza cómo una sirvienta arregla el cabello y sombrero velado de la monarca según las costumbres estéticas de luto mientras, «Richard, su sirviente, deposita en su diván la ropa de Alberto, su chaleco, sus zapatos, sus calcetines. En el cuarto de aseo, llena el jarro con agua caliente, como si su señor fuera a afeitarse». ${ }^{35}$ El retrato oficial de Alberto aparece colgado en segundo término, en penumbra, tras el dosel de una cama (figs. 30 a 35).

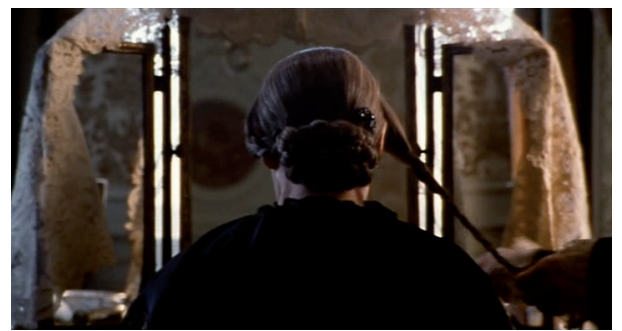

Fig. 30. Una doncella trenza el pelo cano de la envejecida reina viuda en Mrs. Brown.

32. Es en la serie televisiva Victoria donde más relevancia tiene Alberto, si bien continúan siendo las cuitas domésticas con Victoria - por ejemplo, respecto a la educación de sus hijos- aquello que más atención recibe.

33. Daphne Bennet: King Without a Crown: Albert Prince Consort of England 1819-1861, Heinemann, London, 1977, p. 376.

34. Escribiría a su esposa: «My advice to be less occupied with yourself and your own feelings is really the kindest I can give [...] for pain is felt chiefly by dwelling on it and can thereby be heightened to an unbearable extent». Roger Fulford: The Prince Consort, Macmillan, London, 1966, p. 249.

35. Alexandre y D'Aulnoit, Victoria (1819-1901), p. 345. 


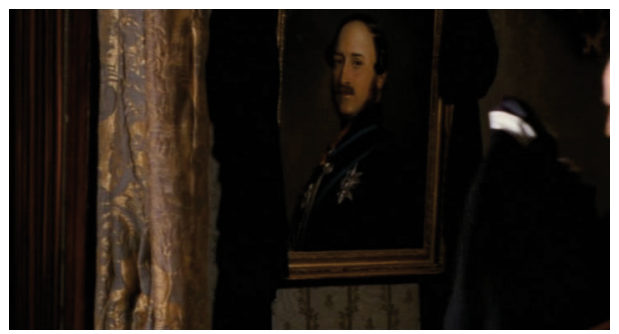

Fig. 31. La cámara atrapa el retrato del príncipe Alberto.

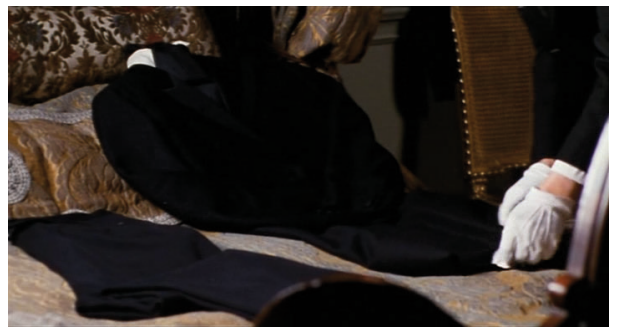

Fig. 32. El plano atiende el movimiento del lacayo dispone el atuendo del príncipe muerto.

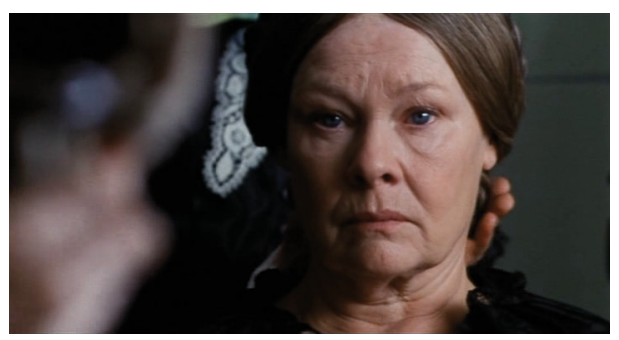

Fig. 33. Victoria reflejada, sombría, en el espejo.

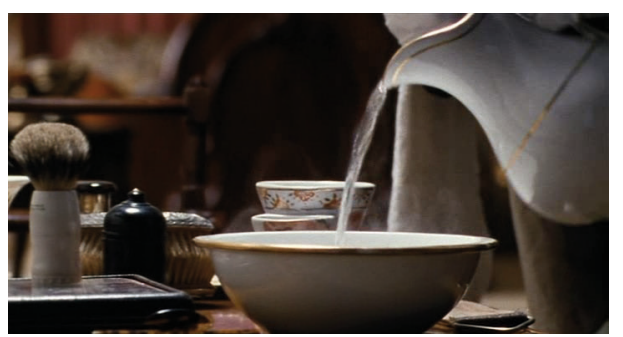

Fig. 34. Los utensilios del aseo del príncipe, preparados diariamente. 


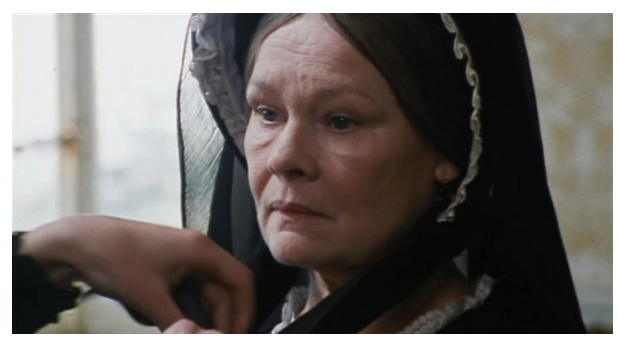

Fig. 35. Una doncella ata a Victoria el sombrero y velo de luto.

De la efigie pintada del príncipe consorte -equivalente a la amargura de su recuerdo-, la cámara se traslada hacia las consecuencias prácticas del duelo, materializadas en una serie de prohibiciones e imposiciones ${ }^{36}$ al servicio y la corte, convertida en «una escuela de vestales viudas» que debían «ocuparse de la llama de la pena de la reina y atender su conveniencia para siempre». ${ }^{37}$ La mirada pasmada e introspectiva de la reina contemplándose en el espejo confirma lo que la voz en off de su secretario privado, Sir Henry Ponsonby (1825-1895), va explicando: que ha hecho llamar a un tal John Brown, mencionado por la reina como el mejor sirviente de Alberto en Escocia, para intentar despertarla del «intento de revivir aquello que nunca puede ser resucitado».

\section{El ESCOCÉS}

Los planos que siguen al montaje alterno recién mencionado encuadran una playa rocosa al aire libre, con pequeñas casitas de piedra, en la que un hombre con barba vestido con kilt camina con un poni blanco. No en balde, sacar a Victoria de su enclaustramiento sería uno de los primeros méritos del apuesto, rudo, directo y leal highlander John Brown (1826-1883)

36. Victoria inmediatamente estableció que el luto por el príncipe consorte «shall be ordered for the longest time in modern times», y así lo cumplió. Vera Watson: A Queen at Home: An Intimate Account of the Social and Domestic Life of Queen Victoria's Court, W. H. Allen, London, 1952, p. 156. Vestida estrictamente de negro de forma vitalicia, rindiendo culto póstumo a su marido tanto en las residencias reales -repletas de bustos, estatuas, fotografías del príncipe y de ella (sola o con sus hijas) rodeando sus imágenes-, como en monumentos públicos - como el Albert Memorial erigido en Hyde Park en estilo neogótico, del que Alberto había sido un decidido impulsor-. La habitación en que murió en Windsor se mantuvo exactamente como estaba en vida de él. Los habitantes del castillo debían hablar susurrando, especialmente durante los primeros años de duelo y las comidas - prácticamente el único momento compartido por la reina con su familia- resultaban agónicos y largos silencios. Nadie tenía permitido salir del enfermizamente frío edificio a menos que la Viuda de Windsor lo hiciera.

37. Longford, Elizabeth: Life With Queen Victoria: Marie Mallet's Letters from Court, 1887-1901, John Murray, London, 1998, p. 310. 
(fig. 36). Llegado a Osborne tres años después de la muerte de Alberto y desprovisto de la pompa y educación cortesanas, contradeciría a Victoria consiguiendo constantemente y para asombro de todos que hiciera lo que él quería, ocupando así una excepcional posición en la vida de ella. De ser cierto que era la celebración del duelo aquello que la mantenía viva, ${ }^{38}$ John Brown supo invertirlo evocando recuerdos felices con el príncipe, mejorando su humor y convenciéndola para cabalgar a diario (fig. 37). La determinación y sinceridad del sirviente se traslada fílmicamente desde su primera conversación con la reina, a quien le espeta que debe echarle de menos (a Alberto) terriblemente, pues nunca pensó verla en semejante estado -balbuceante, imprecisa, llorosa-.

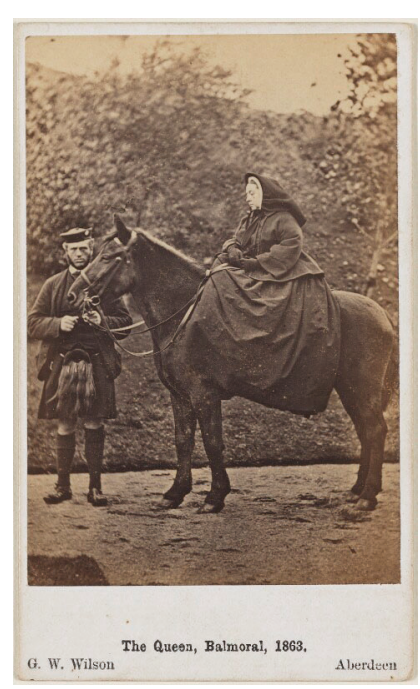

Fig. 36. Georges Washington Wilson, John Brown; Queen Victoria, 1863, $103 \times 62 \mathrm{~mm}$, National Portrait Gallery.

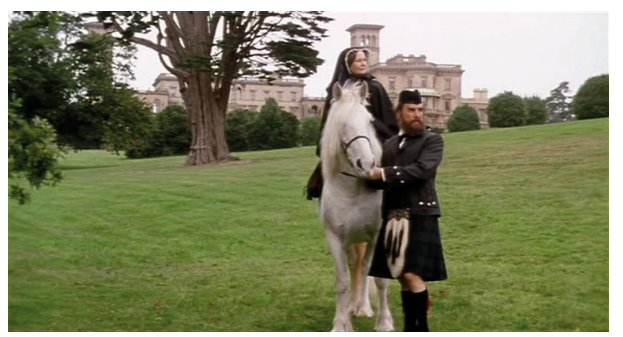

Fig. 37. Primer paseo de Victoria con John Brown en el filme.

38. Según fue envejeciendo, la reina desarrolló un interés e implicación crecientes en la organización de funerales y confección de ropa de duelo, y coleccionó objetos relacionados con la memoria de los muertos -familiares, amigos, o sirvientes-. RAPPAPORT, Queen Victoria, pp. 408-409. 
La distancia inicial marcada por Victoria toma, como en otras ocasiones, carácter espacial, pues el escocés permanece de pie en el jardín junto al poni. desoyendo las órdenes del personal de palacio hasta que su obstinada desobediencia llama la indignada atención de su majestad, que le observa desde una ventana (fig. 38 y fig. 39).

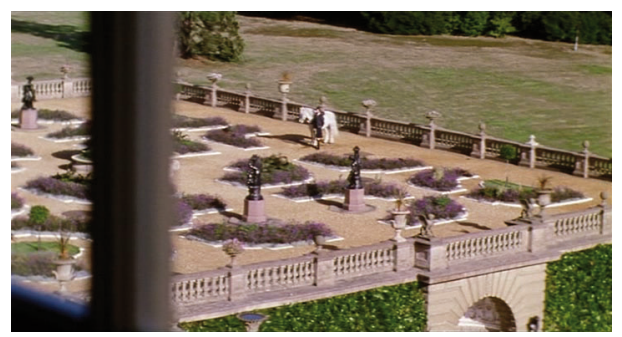

Fig. 38. Plano subjetivo de la mirada de Victoria hacia Brown en el jardín.

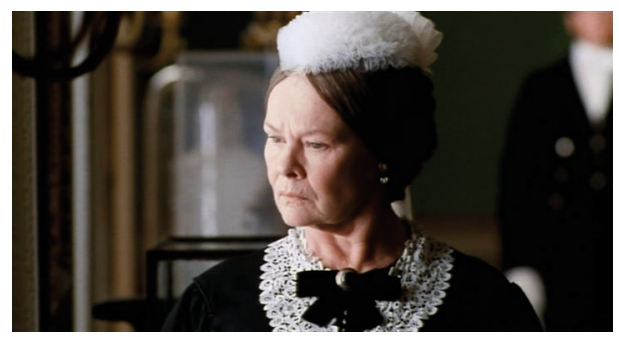

Fig. 39. La reina observa al sirviente escocés desde el palacio.

La estrecha relación entre ambos y su promoción como el más importante miembro del servicio de palacio provocó rumores - públicos y privados,$-^{39}$ alimentados por la reclusión de la reina, que no impidieron que durante los últimos dieciocho años de su vida Brown no se alejara una sola vez de su lado. En beneficio del efecto dramático, el filme de Madden relaciona un parcial retorno a la vida pública de la reina ${ }^{40}$ orquestado por el carismático primer ministro Benjamin Disraeli (1804-1881), con el empeoramiento de la salud de Brown, debilitada por su alcoholismo y negligencia al exponerse, en sus paseos con Victoria, al frío y la lluvia vestido solamente con su tradicional kilt y chaqueta. Tras una fuerte discusión ${ }^{41}$ previa a que la reina vuelva a sus asuntos de

39. Incluso sectores decididamente monárquicos empezaban a cuestionarse el abandono de la reina de sus deberes oficiales, y empezaron a aparecer viñetas satíricas en revistas como Punch, «insinuating that Brown was now not only the power behind the throne but perhaps also had found his way into the Royal bed». RAPPAPORT, Queen Victoria, p. 78.

40. En los años de 1866 y 1867, cediendo ligeramente a la presión parlamentaria, acudió a la apertura del parlamento quejosa y negándose a vestir de forma oficial.

41. De nuevo en beneficio del drama, el filme se toma la licencia de atribuir a Brown el haber convencido a la reina de volver al espacio público, pagando el precio de que ella se sienta traicionada por él. A gritos, en la 
estado y la consecuente separación, Brown -al servicio de la soberana, pero relegado de su puesto privilegiado- todavía protagoniza un último acto heroico: frustrar el intento de magnicidio del irlandés Arthur O'Connor. ${ }^{42}$ Poco después, fallece dejando otra gran ausencia en la vida de la reina. Del mismo modo que sucederá con el munshi, Bertie, el Príncipe de Gales, cuya relación con la reina siempre fue tensa y mutuamente insatisfactoria, ordenaría destruir prácticamente todo recuerdo y objeto relacionado con Brown.

Sin embargo, la historiografía ha rescatado los mencionados arreglos de Victoria para su propio entierro, con múltiples e íntimos recuerdos suyos -incluido el anillo de bodas de la madre de Brown, que él le había regalado-, su placa conmemorativa en el Royal Mausoleum de Frogmor -la única del sepulcro que no pertenece a un miembro de la realeza- y las incansables palabras que Victoria dedica a su sirviente en sus diarios. Sir Henry Ponsonby, secretario privado de la reina, a diferencia de su alter ego ficticio en Mrs. Brown, fue uno de los pocos que, lejos de considerarle una amenaza, avalaron la honestidad de John Brown a pesar de sus modales toscos. ${ }^{43}$

La imagen del busto de Brown haciéndose pedazos es la primera del filme (fig. 40 y fig. 41). Sir Ponsonby, en la última escena, explica que les costó horas recoger los pedazos. No en balde, hilvanar y reconstruir hipótesis y fragmentos escritos o retratados hace más de un siglo y medio es lo que hace Mrs. Brown, proponiendo una reina melancólica, incomprendida, irresponsable y egoísta, obstinadamente encadenada a un fantasma y afectivamente dependiente de otro hombre, cuyo enamoramiento sugiere contenidamente -sin osar desarrollarlo-, desde el gesto y la composición (melodramáticos recursos ante la falta de palabras) (fig. 42).

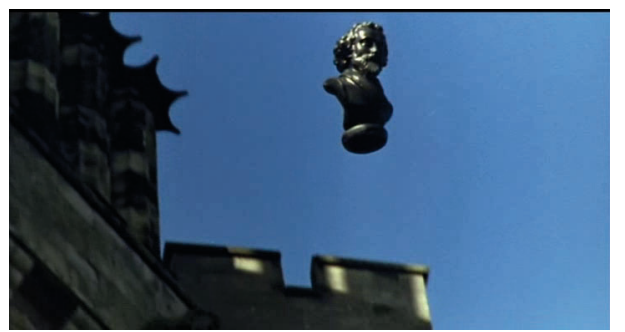

Fig. 40. Primer plano de Mrs. Brown, con el busto cayendo al vacío.

conversación traslada su disgusto, ansiedad y temor de convertirse en el espectáculo de una viuda nerviosa, temblorosa y sola. Hibbert, Queen Victoria, a Personal History; WARd, Yvonne. "The Womanly Garb...».

42. Uno de los siete intentos de asesinato que sufrió Victoria tuvo lugar en febrero de 1872, cuando regresaba del te deum celebrado en la Catedral de St. Paul en agradecimiento a la recuperación del príncipe de Gales de la fiebre tifoidea que hizo revivir el fantasma de la muerte de su padre. O'Connor fue desarmado por Brown, aunque su pistola se reveló como rota e inservible.

43. Los placeres de Brown eran simples - whisky y tabaco-; apenas usó la finca en Balmoral que la reina le concedió, llena de sus regalos personales; carecía de ambición para sí mismo y no le interesaba ejercer influencia política en la reina ni la opinión de la clase alta. Tal era su «aterradora lealtad» que «in an earlier, less civilized age he would have killed for her as readily as he carried her tea tray». STANLEY WEINTRAUB: Victoria, John Murray, London, 1996, p. 365. 


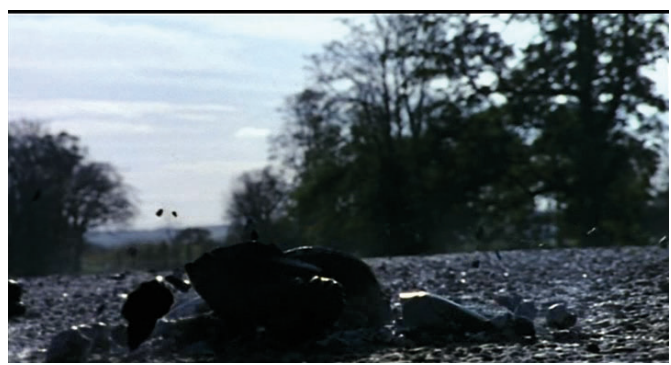

Fig. 41. El busto se estrella contra el suelo.

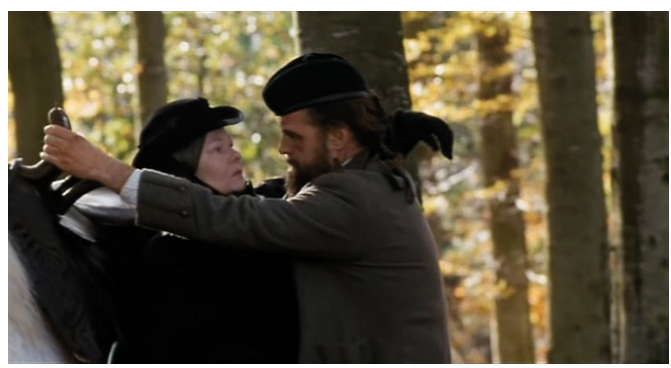

Fig. 42. Contenida cercanía física entre Brown y Victoria en Mrs. Brown.

\section{El MUNSHI}

Si en Mrs. Brown la reina termina despidiéndose de Brown en su lecho de muerte, en Victoria $\mathcal{E}$ Abdul es Karim quien acompaña sus últimos suspiros (fig. 43 y fig. 44).

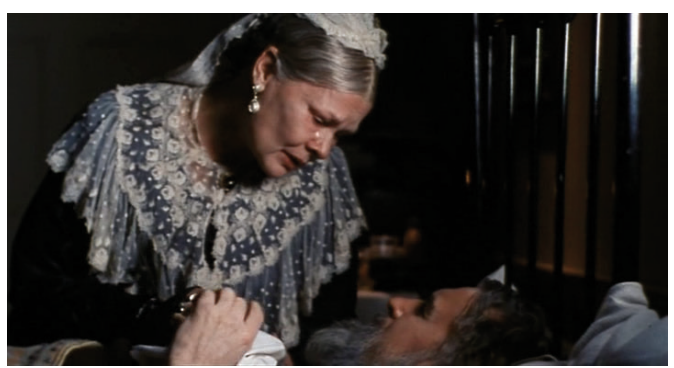

Fig. 43. Lecho de muerte de John Brown en Mrs. Brown. 


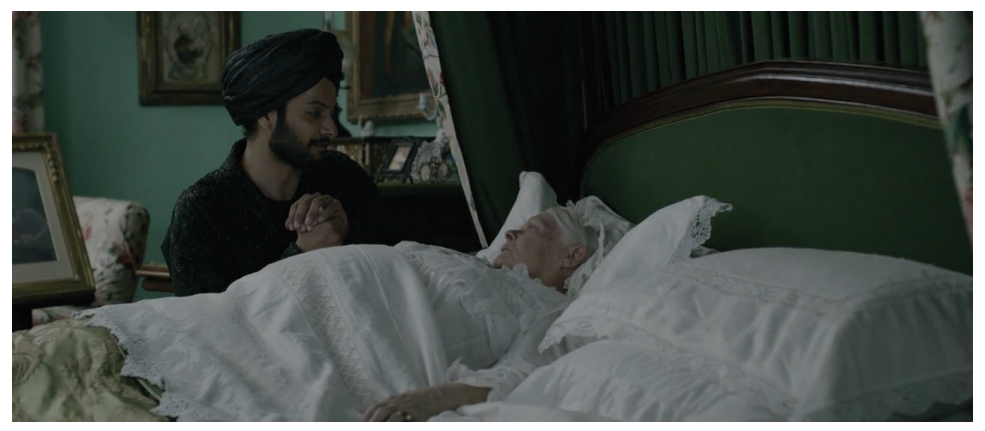

Fig. 44. Karim con Victoria, en su lecho de muerte.

El esquema argumental del filme -aunque no su tono- es muy similar al del anterior: un personaje masculino exótico -en esta ocasión indio-, alto, bien parecido, más joven que la reina, llega a palacio -a propósito de la celebración de su Jubileo de oro en 1887- y a ella le complace que la atienda, mientras que la corte y el servicio, sin excepción, abominan de su presencia y cercano contacto con Victoria. La reina desea aprender más sobre la India y encarga a Karim, pronto considerado su munshi, su maestro, que le enseñe indostánico. ${ }^{44}$ Como en diversas ocasiones en los otros filmes, el montaje paralelo hermana -y a la vez contrasta- a los protagonistas. La encargada del vestuario y una sirvienta levantan -literalmente- a la anciana reina, mientras los sirvientes hindús viajan en barco hacia Inglaterra para cumplir con su papel en la celebración. La puesta en escena de los aposentos de Buckingham Palace es contrapuesta a la de las hamacas en las que duermen ellos, en la bodega del barco. La preparación de la reina para el Jubileo frente al espejo va seguida de la llegada de Karim a Windsor y los paralelismos formales continúan mientras ambos son vestidos (fig. 45 y fig. 46). Sin embargo, el rostro de ella no se mostrará hasta que se siente a presidir el banquete en el que entran en contacto por primera vez.

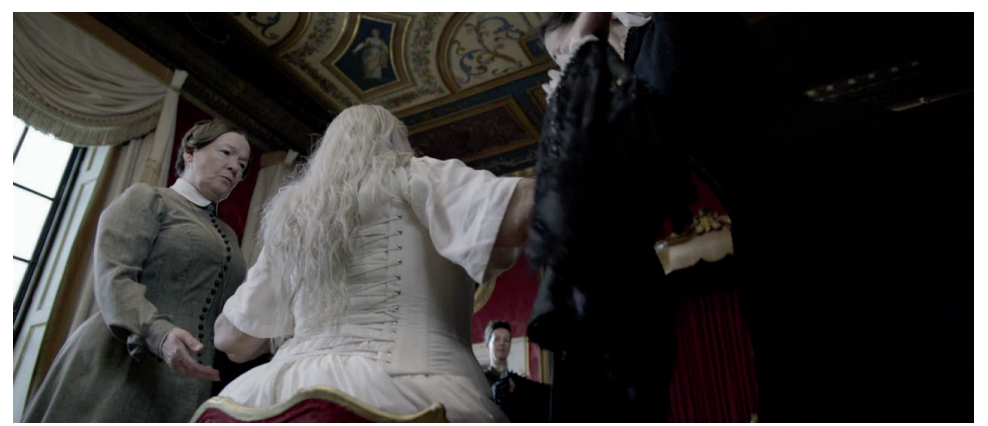

Fig. 45. La reina es vestida por sus doncellas.

44. Sushila Ansand: Indian Sahib: Queen Victoria's Dear Abdul, Duckworth, London, 1996. 


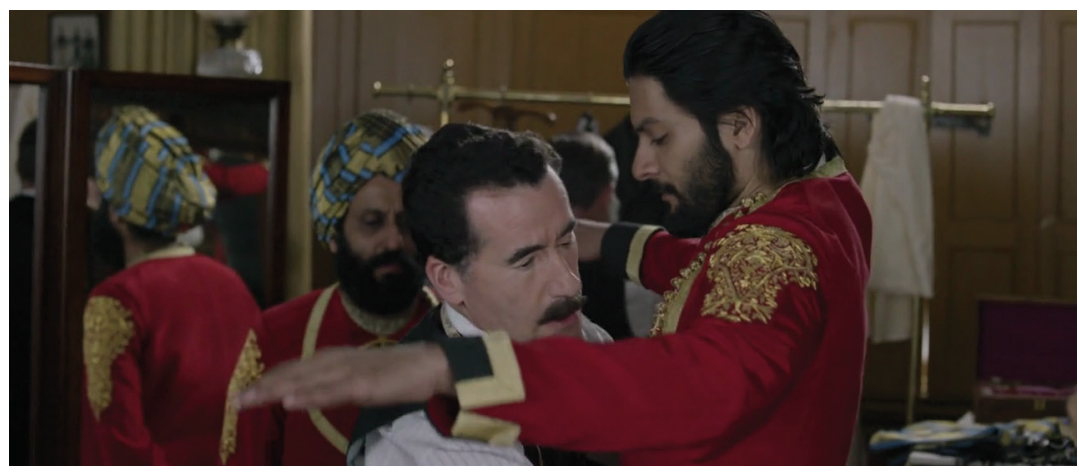

Fig. 46. Visten a Karim para la ceremonia.

Abundan, en la entrada de los indios en el castillo y sus primeras horas allí, los contrapicados que engrandecen el lugar, trasladando el visible asombro de Karim (fig. 47 y fig. 48).

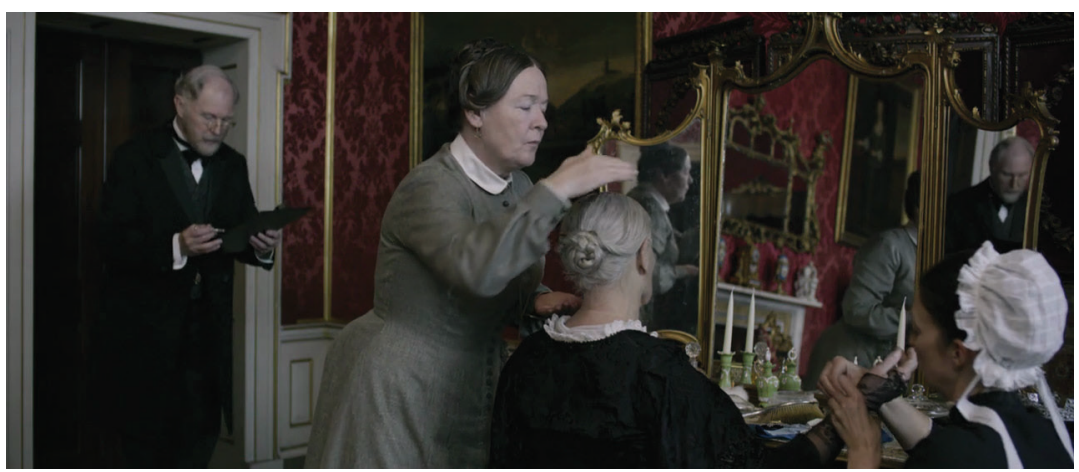

Fig. 47. El plano esquiva ofrecer el rostro de la reina en el espejo.

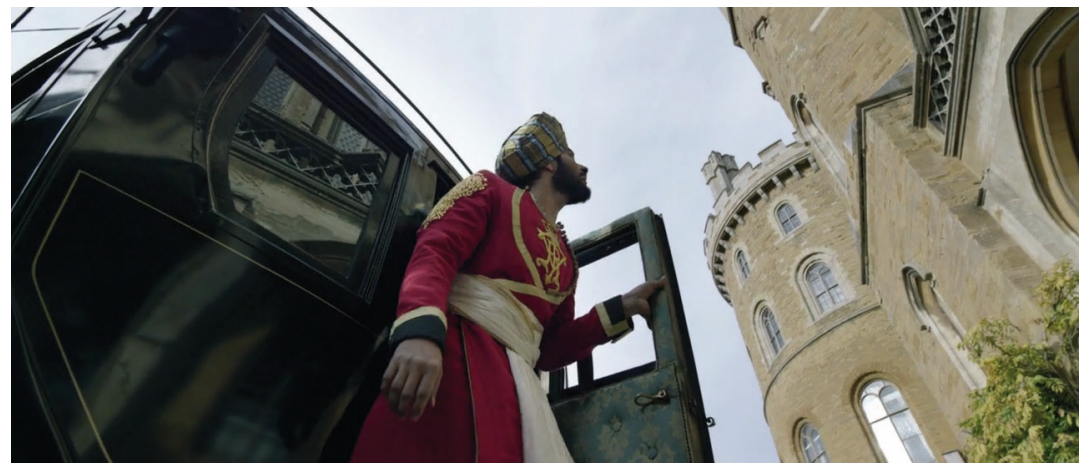

Fig. 48. Plano aberrante que representa la impresión de Karim ante el castillo de Windsor. 
El carácter más caricaturesco de los personajes y los rituales de corte se traducen formalmente en los encuadres con marcadas diagonales formadas por los invitados dispuestos con precisión milimétrica, contestados por larguísimas colas de mayordomos que traen y llevan la comida. El revuelo y las carreras que implica un plato de sopa pone en evidencia un dispositivo que se representa desde el lenguaje fílmico como excesivo, por ejemplo, mediante los acusadísimos contrapicados que, más que engrandecer, ridiculizan a los mozos que anuncian con trompetas los diferentes eventos, ya en el salón de Windsor, particularmente cuando llega el mohúr -la emblemática moneda india con efecto de MacGuffin, cuyo pequeño tamaño decepciona incluso al mayordomo principal- y el sirviente indio que ha viajado muy a su pesar para entregarlo a la reina, no tiene nada que llevar en las manos (figs. 49 a 52).

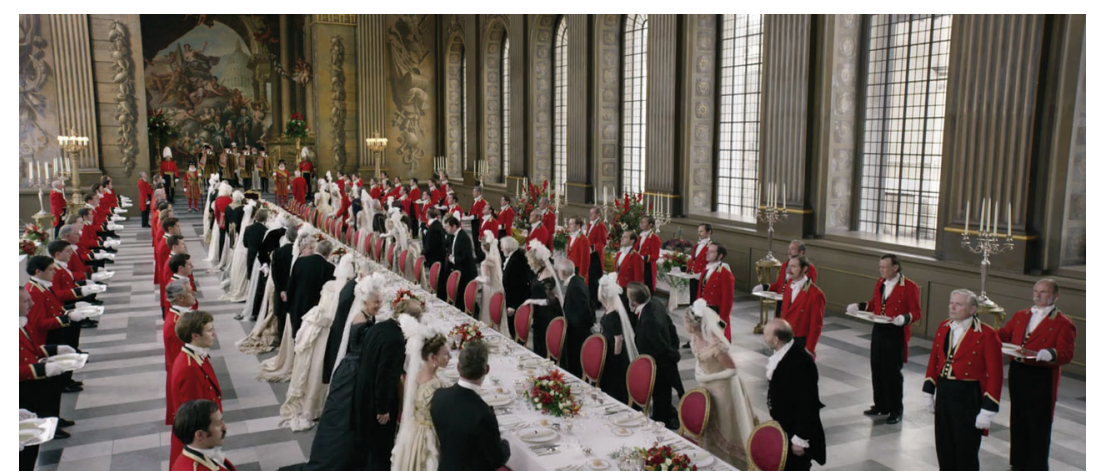

Fig. 49. El banquete cruza en una destacada diagonal el plano.

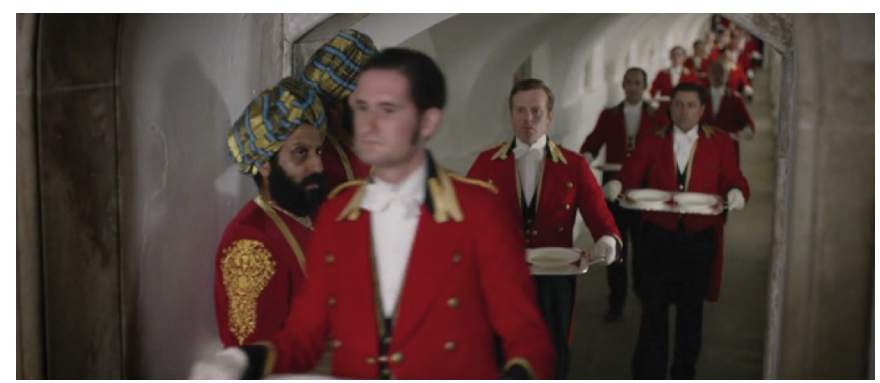

Fig. 50. Las diagonales se contestan compositivamente representando también a la servidumbre. 


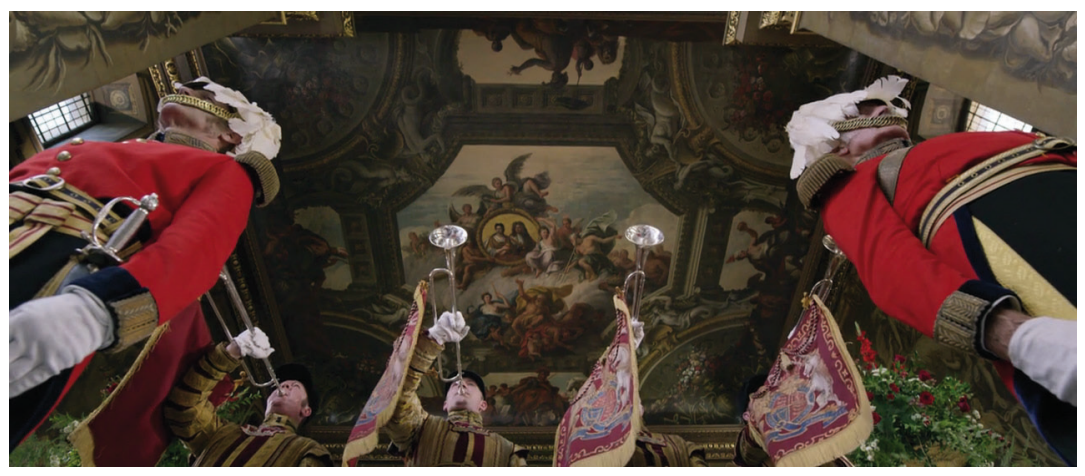

Fig. 51. Acusado contrapicado de los sirvientes.

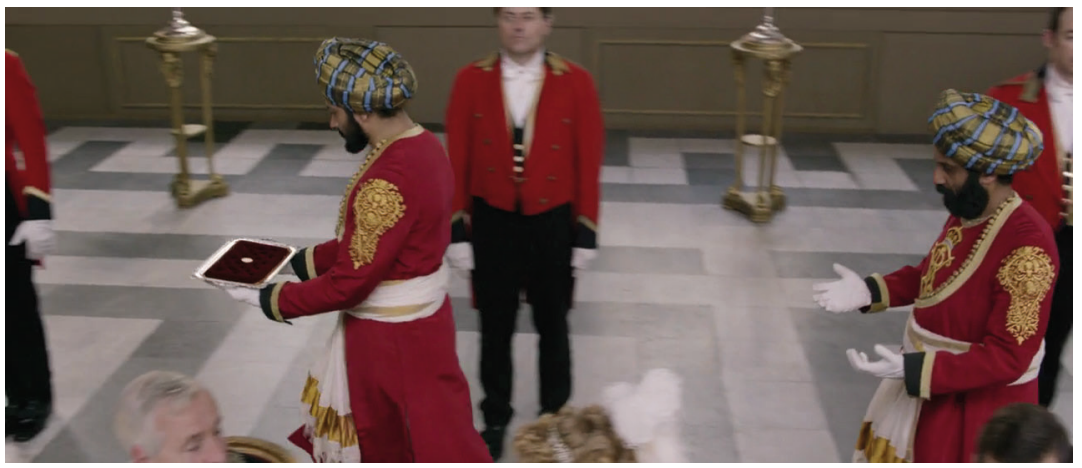

Fig. 52. Fotograma de Victoria y Abdul, 2015

La imagen de este segundo sirviente, Mohammed (Adeel Akhtar), que ha cruzado medio mundo para desfilar disfrazado con las manos vacías, antecede a la crítica que la película desarrolla respecto al imperialismo británico. Más allá del descarado racismo de conciencia imperialista con que se dibuja a la élite británica y las abiertas quejas del personaje, deprimido y deteriorado por el frío británico, una serie de encuadres le muestran enfermo, tembloroso y chantajeado por el príncipe heredero, convocando iconográficamente ecos actuales en su problemática (fig. 53 y fig. 54). 


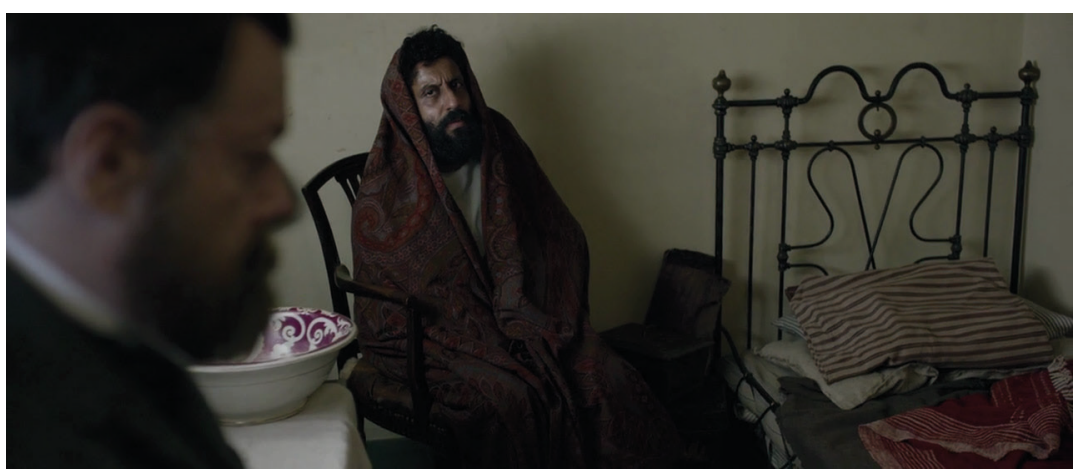

Fig. 53. Contrapicado de Mohammed, enfermo y extorsionado por el Príncipe de Gales.

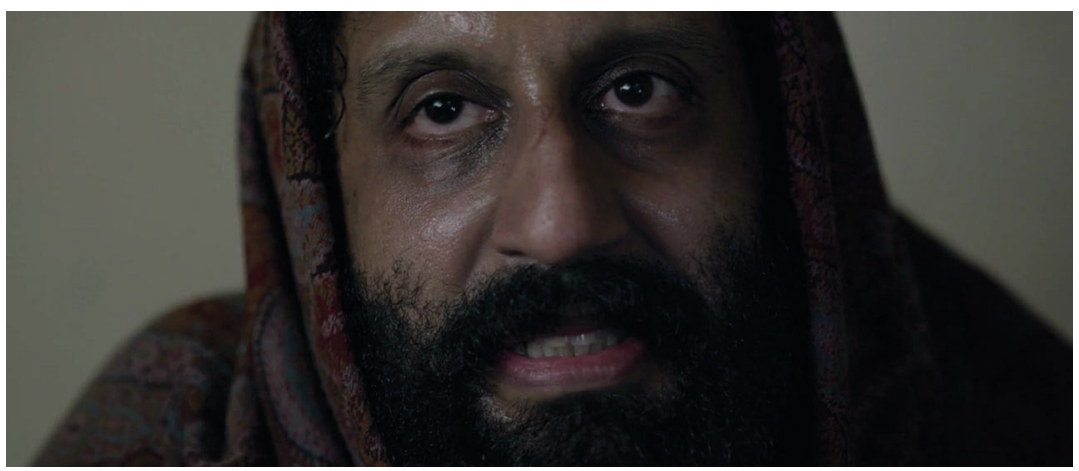

Fig. 54. Intenso primer plano de Mohammed, reaccionando con desprecio al chantaje.

Lo mismo sucede con la violencia con la que el personal de palacio, encabezado por el ya rey Eduardo VII, entra en la casa en la que vive el munshi con su esposa y suegra zarandeándolas, revolviendo sus objetos y destruyendo -como ya hiciera con John Brown- toda prueba documental de su relación con la reina muerta. La banda sonora, el llanto de Karim y el efecto iconoclasta que genera la fotografía de ambos ardiendo (fig. 55 y fig. 56) termina incidiendo en la inmediata expulsión del munshi, que se retiró a la finca que la reina le había concedido en la India, y -de nuevo en beneficio del clímax final- contrasta con la emotiva despedida dispuesta mediante primerísimos primeros planos de los dos. 


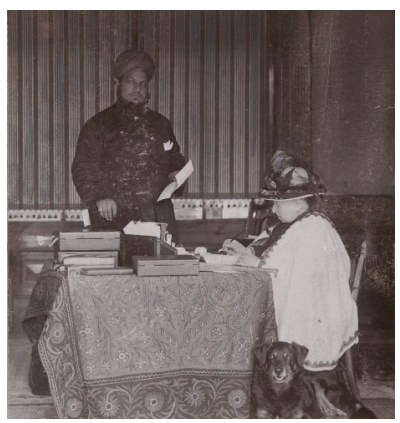

Fig. 55. Robert Milne, Hafiz Abdul Karim; Queen Victoria with her dog Noble, 1897, $139 \times 99$ mm, National Portrait Gallery (fragmento).

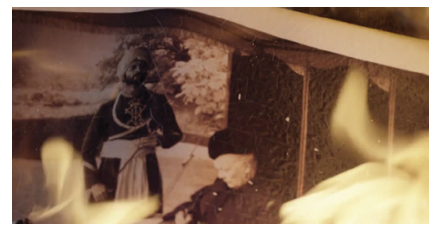

Fig. 56. La recreación cinematográfica de una de las fotografías de Victoria con el munshi, ardiendo.

En este último filme ya no es la reina -que deja hacer al resto, aburrida y por inercia - la responsable de lo excéntrico del funcionamiento de palacio, como sucedía en Mrs. Brown, sino que el lenguaje cinematográfico lo trata como tal. La reina de Frears es también melancólica, irascible y obstinada, ${ }^{45}$ pero aquello en que la narrativa insiste es en la inocencia e ilusión casi infantil que le despierta el munshi.

\section{LOS SUSURROS}

Los filmes, hijos de los medios de masas que nacían poco antes de la muerte de la reina, pero a tiempo de capturarla en celuloide, indagan en la imagen de la monarca que inundó y fue reclamada por -en ocasiones, a su pesar- la cultura visual de su tiempo. El anclaje del punto de vista en Victoria vincula los tres relatos. La mirada de la cámara, la composición, la iluminación, la banda sonora y el montaje renuncian a una narración distante para empatizar con la subjetividad de la reina, dando prioridad en todo momento a su vida sentimental frente a la política, que estuvo marcada por los afectos y desafectos de

45. Como realmente lo fue cada vez que su personal y familia se manifestaron en contra de John Brown y, sobre todo, de Karim, desoyendo cualquier crítica hacia ellos. 
la anterior pese a los esfuerzos del príncipe consorte en inculcarle su propia capacidad de juzgar racional, fría y objetivamente cada situación como monarca. La enunciación se enamora, se aflige, se indigna con ella para inventar a la soberana en cada ocasión, vinculándola siempre a uno de los tres hombres mencionados. De este modo, la imagen en movimiento tantea y matiza, desde la ficción, a la efigie fotográfica, institucional, decimonónica de Victoria.

El cine, como la historiografía, ensambla piezas -imágenes- necesariamente dispersas para hacerlas significar poniéndolas en contacto, encadenándolas de modo que unas condicionan, reescriben irremediablemente a las otras. En los filmes que bucean en la historia y el arte para nutrirse de ellos e idear, repensar y representar un personaje histórico -y su época, y sus conflictos- acudiendo a referentes previos, la constelación creada por el montaje resulta laberíntica. La memoria de los personajes históricos toma vida propia en el cine sin que la historiografía pueda, siempre, corregir sus inclinaciones. Tampoco esta última puede vanagloriarse de tener, nunca, la última palabra, pues en virtud de su propia honestidad está condenada a corregirse a sí misma constantemente. Un susurro pronunciado en un lecho de muerte, silente entre las páginas de un diario íntimo durante siglos, tiene la capacidad de quebrar la imagen blindada del ser aludido. Así pudo suceder con la resucitada confesión del reverendo Norman Macleod, capellán de Victoria, que en su lecho de muerte confesaba haberla casado en secreto con John Brown, remordimiento filtrado desde los cuchicheos discretos de la antesala de la muerte a la palabra escrita que, aunque fuera redactada en privado para no ser leída, terminó siendo objeto de debate entre historiadores ${ }^{46}$ A esta cuestión sobrevuela el interrogante de la verdadera potencia del dato empírico, cuando independientemente del mismo, el murmullo hablado y escrito del pasado y la ficción cinematográfica del presente han decidido dar consistencia, en este caso, al romance de una reina.

\section{BibliografíA}

Alderson, Andrew: «Victoria 'did become Mrs Brown'», The Telegraph, 2003.

Alexandre, Philippe y D’Aulnoit, Béatrix: Victoria (1819-1901). Reina y emperatriz, Edhasa, Barcelona, 2001.

Ansand, Sushila: Indian Sahib: Queen Victoria's Dear Abdul, Duckworth, London, 1996.

Ashdown, Dulcie: Queen Victoria's Mother, Robert Hale, London, 1974.

Beem, Charles: The Lioness Roared: The Problems of Female Rule in English History, Palgrave Macmillan, New York, 2008.

Benjamin, Walter: Sobre la fotografia, Pre-Textos, Valencia, 2004.

Bennet, Daphne: King Without a Crown: Albert Prince Consort of England 1819-1861, Heinemann, London, 1977.

Benson, A. C. y Escher, Vicount (Eds.): Letters of Queen Victoria 1837-1861, John Murray, London, 1911.

46. Andrew Alderson: «Victoria 'did become Mrs Brown'», The Telegraph, 2003. 
Diamond, Frances y TAYlor, Ann: Crown and Camera: The Royal Family and Photography, Penguin, Harmondsworth, 1987.

Esher, Viscount (ED.): The Training of a Sovereign, John Murray, London, 1914.

Ford, Elizabeth A. y Mitchell, Deborah C.: Royal Portraits in Hollywood. Filming the Lives of Queens, The University of Kentucky Press, Lexington, 2009.

Fulford, Roger: The Prince Consort, Macmillan, London, 1966.

Hardy, Alan: Queen Victoria Was Amused, John Murray, London, 1976.

Hibbert, Cristopher: Queen Victoria, a Personal History, Harper Collins, London, 2000.

Hudson, Katherine: A Royal Conflict: Sir John Conroy and the Young Victoria, Hodder and Stoughton, London, 1994.

Kinzler, Julia: "Visualising Victoria: Gender, Genre and History in The Young Victoria (2009)», en Neo-Victorian Studies, 4 (2), 2011, pp. 49-65.

Lamont-Brown, Raymond: John Brown: Queen Victoria's Highland Servant, Sutton, 2000.

Longford, Elizabeth: Life With Queen Victoria: Marie Mallet's Letters from Court, 18871901, John Murray, London, 1998.

Plunkett, John: Queen Victoria: First Media Monarch, Oxford University Press, Oxford, 2003.

Rappaport, Helen: Queen Victoria. A Biographical Companion, ABC-CliO, Santa Bárbara, 2003.

St. Aubyn, Giles: Queen Victoria: A Portrait, Siclair Stevenson, London, 1991.

Strachey, Lytton y Fulford, Roger (eds.): The Grenville Memoirs, Macmillan, London, 1938.

TisDall, E. E. P.: Queen's Victoria's Private Life, Jarrolds, London, 1961.

WARD, YvONNE: «The Womanly Garb of Queen Victoria's Early Motherhood, 1849-1842», en Women's History Review, 8 (2), 277-294, 1999.

Watson, Vera: A Queen at Home: An Intimate Account of the Social and Domestic Life of Queen Victoria's Court, W. H. Allen, London, 1952.

Weintraub, Stanley: Victoria. John Murray, London, 1996. 